\title{
Spectral Characteristics of the Antarctic Vegetation: A Case Study of Barton Peninsula
}

\author{
Junhwa Chi $\mathbb{1}$, Hyoungseok Lee * ${ }^{\mathbb{C}}$, Soon Gyu Hong and Hyun-Cheol Kim $\mathbb{1}$
}

Citation: Chi, J.; Lee, H.; Hong, S.G.; Kim, H.-C. Spectral Characteristics of the Antarctic Vegetation: A Case Study of Barton Peninsula. Remote Sens. 2021, 13, 2470. https:// doi.org $/ 10.3390 /$ rs 13132470

Academic Editor: Gareth Rees

Received: 17 May 2021

Accepted: 22 June 2021

Published: 24 June 2021

Publisher's Note: MDPI stays neutral with regard to jurisdictional claims in published maps and institutional affiliations.

Copyright: (c) 2021 by the authors. Licensee MDPI, Basel, Switzerland. This article is an open access article distributed under the terms and conditions of the Creative Commons Attribution (CC BY) license (https:/ / creativecommons.org/licenses/by/ $4.0 /)$.
Korea Polar Research Institute, Incheon 21990, Korea; jhchi@kopri.re.kr (J.C.); polypore@kopri.re.kr (S.G.H.); kimhc@kopri.re.kr (H.-C.K.)

* Correspondence: soulaid@kopri.re.kr

\begin{abstract}
Spectral information is a proxy for understanding the characteristics of ground targets without a potentially disruptive contact. A spectral library is a collection of this information and serves as reference data in remote sensing analyses. Although widely used, data of this type for most ground objects in polar regions are notably absent. Remote sensing data are widely used in polar research because they can provide helpful information for difficult-to-access or extensive areas. However, a lack of ground truth hinders remote sensing efforts. Accordingly, a spectral library was developed for 16 common vegetation species and decayed moss in the ice-free areas of Antarctica using a field spectrometer. In particular, the relative importance of shortwave infrared wavelengths in identifying Antarctic vegetation using spectral similarity comparisons was demonstrated. Due to the lack of available remote sensing images of the study area, simulated images were generated using the developed spectral library. Then, these images were used to evaluate the potential performance of the classification and spectral unmixing according to spectral resolution. We believe that the developed library will enhance our understanding of Antarctic vegetation and will assist in the analysis of various remote sensing data.
\end{abstract}

Keywords: Antarctic vegetation; Barton Peninsula; field spectroscopy; King George Island; lichen; moss; spectral characteristics; spectral library

\section{Introduction}

Recent interest in climate change and global warming has affected the distribution and function of vegetation by changing the environmental conditions of ecosystems [1]. Since the Antarctic ecosystem is particularly sensitive to environmental change, studying its responses can enhance our understanding of such changes [2-6]. The monitoring of terrestrial biodiversity in the Antarctic Peninsula and the South Shetland Islands, which are some of the most rapidly warming areas in the world [6,7], is vital as a proxy for climate change.

Detailed information on the maritime biodiversity in Antarctica has been collected via field surveys, but this information is limited to the areas most frequently visited by researchers, primarily near Antarctic research stations. Therefore, on King George Island, the largest of the South Shetland Islands and the most concentrated region of Antarctic research stations, various biodiversity monitoring studies via field surveys have been conducted. In the Maxwell Bay area of King George Island, vegetation cover was surveyed [8], and the species density of bryophytes and lichens was calculated for the Barton Peninsula around King Sejong Station [9]. Due to the extreme environmental conditions, only two species of flowering plants, Deschampsia antarctica and Colobanthus quitensis, grow in small and sparse patches; however, cryptogamic species, including 33 bryophytes (mosses) and 62 lichens, are dominant in most snow-free regions [8,9]. Changes in the lichen community diversity and composition of a deglaciated gradient were analyzed using five $50 \times 50 \mathrm{~cm}$ grids at 24 sites in the Potter Peninsula [10]. The 
present study reports that the patterns of these Antarctic lichen communities are dynamic and highly heterogeneous due to a strong influence of microsite factors and macroclimate variables. In Admiralty Bay, biomass and net annual production patterns were analyzed for four moss species in Antarctica [11], and the driving mechanisms of vegetation, including soil characteristics and landscape elements (altitude and geomorphological variations), were investigated [12] in the surrounding area of Arctowski Station. A distribution map was generated for 35 vegetation communities of the Keller Peninsula [13], and the lichen biota dynamics of Lions Rump for the past 20 years were characterized, showing that the most significant changes had taken place in the forefield of a glacier and on the young moraines [14]. In addition, the distributions of the representative flowering plant Deschampsia antarctica [15] and of mosses [16] were surveyed and compared between the South Shetland Islands and the Antarctic Peninsula.

However, periodic field surveys of extended areas are financially and physically costly, and the human activity can potentially destroy or disturb the ecosystem. Additionally, survey-based approaches maintain inherent uncertainty when quantifying vegetation cover and variations over relatively long time periods. As an alternative, remote sensing techniques are widely used to periodically monitor quantitative and qualitative states of extensive and/or inaccessible regions. Several studies have been conducted to assess polar vegetational biodiversity using remote sensing approaches over the past decade. Théau et al. [17] used a classification method and spectral mixture analysis for mapping several types of lichen over Northern Quebec using Landsat imagery. They acquired field data using a helicopter and determined the types and percent of coverage by visual inspection. Large-scale mapping analyses using the normalized difference vegetation index (NDVI) from medium-resolution Landsat [18] and SPOT [19] images have been conducted; however, detailed information from these studies is not available due to the limited spatial and spectral resolution of the images and ground truthing efforts. Nonetheless, such research has suggested that a combination of remote sensing data and techniques could potentially help obtain information. Shin et al. [20] used a spectral mixture analysis technique to quantify vegetation abundance at the sub-pixel level from high-resolution KOMPSAT-2 (Korea Multi-Purpose Satellite-2) and QuickBird images of the Barton Peninsula; however, they employed image-driven endmembers instead of field spectra. Liu and Treitz [21] used ground-based near-infrared (NIR) images to develop a vegetation cover model for the Canadian High Arctic, and then applied this model to high-resolution satellite images to examine the spatio-temporal patterns of the vegetation cover over the extended areas. Sun et al. [22] investigated vegetation abundance and health mapping from WorldView2 data using spectral mixture analysis in the Fildes Peninsula and Ardley Island, King George Island. They categorized mosses and lichens according to their associated health conditions and acquired reference field spectra over approximately 300-1000 nm for large sampling plots $(2 \mathrm{~m} \times 2 \mathrm{~m})$, which are suitable for obtaining high resolution satellite data. Accordingly, past vegetation mapping studies of remote sensing data have focused on the analysis of vegetation/spectral indices and on the classification/unmixing of a few vegetation species or conditions due to the relative lack of spectral information and images of the Arctic/Antarctic vegetation.

Incorporating the field spectra of the target areas into the remote sensing analyses can greatly assist with the assessments of inaccessible areas. A spectral library is a set of digital reflectance spectra measured in the laboratory or the field, or remotely by air or spacecraft. They are employed to support imaging spectroscopy studies of the Earth and other planets and include informative wavelength data of both natural and artificial surfaces, such as rocks, minerals, soils, vegetation, snow, and ice [23]. A spectral library can play an important role in identifying the components of unknown targets and quantifying their abundance in mixed pixels. Widely used spectral libraries are contributed to by the Advanced Spaceborne Thermal Emission Reflection Radiometer (ASTER), the NASA Jet Propulsion Laboratory (JPL), the Johns Hopkins University, and the United States Geological Survey (USGS). However, these spectral libraries have been primarily developed 
for use in mid-latitudinal regions. As the landscapes of the polar regions are quite different, the current libraries may not be applicable for interpreting the ecosystems and landcover types in the Antarctic region. Limited research has been aimed at developing a spectral library of polar vegetation. Goswami and Matharasi [24] developed a vegetation spectral library for the Arctic, Antarctic, and Chihuahuan Desert regions using a hand-held portable spectrometer in the visible and NIR (VNIR) wavelength range. Calvino-Cancela and MartinHerreroin [25] developed a spectral library for 13 representative moss and lichen species in the Barton Peninsula in the VNIR wavelength range $(380-1000 \mathrm{~nm})$. Their classified fieldmeasured spectra showed high overall accuracy in principal component analysis-linear discriminant analysis. However, the analysis also concluded that some species, such as Deschampsia and Prasiola, were challenging to discriminate using their library spectra.

Although the spectral library is crucial for quantitative remote sensing analysis, particularly for inaccessible or difficult-to-access locations such as the polar regions, limited spectral information for ground objects in the polar regions is available. This study had two research goals: (1) the development of a spectral library for Antarctic vegetation; and (2) the investigation of the spectral characteristics of Antarctic vegetation to determine which spectral ranges are the most effective for identifying Antarctic vegetation in remote sensing data. To this end, we first developed a spectral library for 16 representative vegetation species and decayed moss, including mosses, lichens, vascular plants, and one alga often discovered in the ice-free areas of Antarctica. Iterative field spectral data across the visible-shortwave-infrared (SWIR) range (400-2500 nm) were collected for homogeneous vegetation patches and then compiled to generate representative spectra. Both spectrometers and hyperspectral imaging sensors typically use the VNIR (400-1000 nm), SWIR (1000-2500 nm), or full-spectrum (i.e., VNIR-SWIR; 400-2500 nm) ranges. As VNIR sensors are lighter, cheaper, and have a better signal-to-noise ratio than SWIR or full-spectrum sensors, using a VNIR spectrometer or integrating a VNIR imaging sensor to a small unmanned aerial vehicle (UAV) has fewer technical challenges. Therefore, along with developing a spectral library of the Antarctic vegetation species over a full-spectral range, analyses were carried out using spectral discrimination measures to observe the spectral characteristics and potential separability of the Antarctic vegetation by wavelength range. Since sufficient remote sensing images with corresponding surveyed data over the study area are unavailable, artificial images were created and modeled using the developed spectral library, field information, and spectral response functions of widely used remote imaging sensors. The potential performance of the vegetation discrimination was then evaluated for practical classification and unmixing tasks. In particular, we addressed the importance of SWIR wavelengths in discriminating or quantifying Antarctic vegetation species effectively.

\section{Materials and Methods}

\subsection{Study Area}

The Barton Peninsula is located between $62.12^{\circ} \mathrm{S}$ and $62.14^{\circ} \mathrm{S}$ and $58.42^{\circ} \mathrm{W}$ and $58.48^{\circ} \mathrm{W}$ in the southwest of King George Island, the largest of the South Shetland Islands (Figure 1). The elevation of the peninsula ranges only from 0 to $266 \mathrm{~m}$, but the topography is complex [26]. A large part of the ground area is covered with snow throughout the year; however, during the summer, $\sim 12 \mathrm{~km}^{2}$ of the regions near the coastal area are snow-free. Soils generally lack nutrients and organic matter, except near seabird nesting sites and penguin rookeries [27]. The climate is relatively warmer, more humid, and milder than that of continental Antarctica, as is more typical of the polar oceanic climate. Based on meteorological records from the Korean Antarctic King Sejong Station in the Barton Peninsula, the annual mean values for this region are: $-1.6{ }^{\circ} \mathrm{C}$ surface air temperature, $89 \%$ relative humidity, and wind speeds of $8.0 \mathrm{~m} \cdot \mathrm{s}^{-1}$ [28]. 


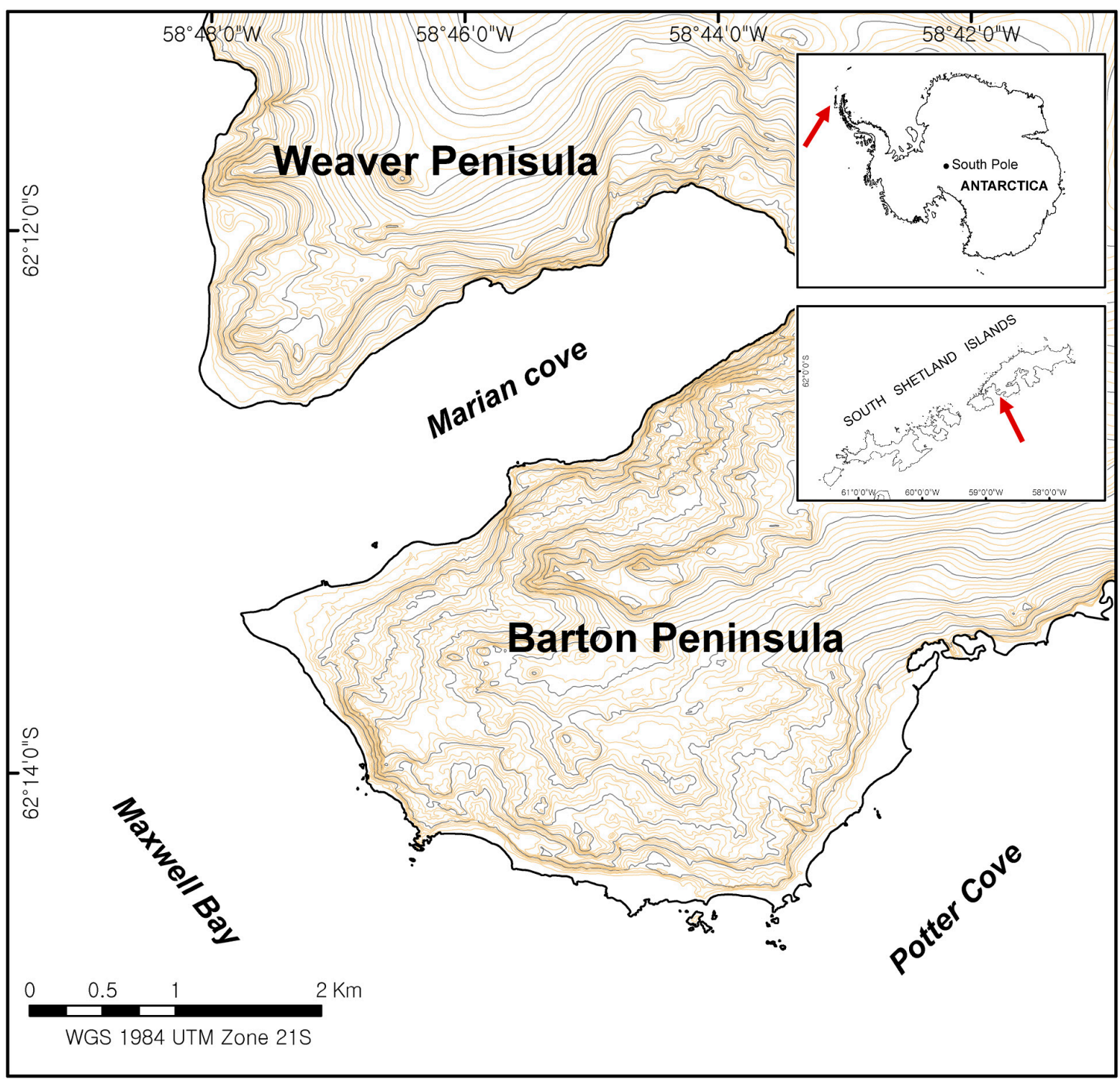

Figure 1. Location and geographic map of Barton Peninsula in King George Island, the largest of the South Shetland Islands.

\subsection{Measurement of Vegetation Spectra}

Surface features have unique signals similar to fingerprints, one of the most wellknown biometrics for human identification due to their uniqueness and consistency over time, referred to as spectral reflectance. Different surface objects reflect and absorb electromagnetic radiations in different ways according to their physical and chemical states. Spectral reflectance is a measure of how much energy a surface reflects at a specific wavelength [29]. Generally, in the field procedures employed to acquire reflectance spectra, the flux reflected from a level reflectance reference surface such as a Spectralon panel is first measured, and then the flux reflected from the subject (e.g., vegetation species in this study) is measured. In this study, an ASD Fieldspec 4 spectrometer (Malvern Panalytical Ltd., Malvern, UK) was used to collect field spectra across the 350 to $2500 \mathrm{~nm}$ wavelength range at a spectral resolution of $1 \mathrm{~nm}$. Due to the high and fast-changing cloud cover over the study area, the spectra were measured with a contact probe, which had a stable halogen krypton light source attached to the mount of the optic cable. The light source of the contact probe was aligned at a fixed illumination zenith of $23^{\circ}$ to the probe body to minimize issues of variable illumination from the surface topography, thereby allowing for the rapid acquisition of spectra at any time of day. The optical cable of the spectrometer 
was mounted to the contact probe at a fixed view zenith angle of $35^{\circ}$ in the same azimuth of the probe axis as the light source [30].

Field campaigns were carried out in selected areas of the Barton Peninsula in the Antarctic summer season, from 17 January to 14 February 2019. As there were no rain or snow events before the acquisition of the field spectra, the impact of water content was minimized. Table 1 displays the scientific names and descriptions of species surveyed in this study. Decayed moss was often observed as mixed or next to other living vegetation in the study area, and we thought it was one of the major components of the ground surface of this area. However, it was difficult to distinguish spectral differences between types of decayed moss. Since the homogeneous and pure targets for 16 vegetation species and decayed moss were first localized to within the field of view, there were mostly no mixed signals in the selected targets. At least 20 individual patches per species were selected, and ten iterative measurements were conducted for each patch. The size of each patch depended on species type and field conditions, but it was a minimum of $5 \mathrm{~cm} \times 5 \mathrm{~cm}$. Spectra for each patch were acquired on different days and at different locations in the Barton Peninsula during the field campaign period. ASD Fieldspec 4 consists of three spectral detectors (relative to the 350-1000 nm, 1001-1800 nm, and 1801-2500 nm wavelength ranges) to capture the full spectral range. The measured spectra often exhibited spectral discontinuities at the borders between these three ranges owing to insufficient sensor warm-up and inhomogeneities of the targets within the field of view [31,32]. These inter-channel radiometric steps were corrected using a radiometric inter-channel jump correction method [31]. To build a spectral library, the reflectance spectra of the 16 species and decayed moss were averaged, with the exclusion of all abnormal spectra and noisy data, across the 350 to $400 \mathrm{~nm}$ wavelength range.

Table 1. Scientific names and descriptions of the 16 representative vegetation species in Barton Peninsula [9].

\begin{tabular}{|c|c|}
\hline Species & Description \\
\hline \multicolumn{2}{|l|}{ Mosses } \\
\hline Andreaea spp. & $\begin{array}{l}\text { Very common and dominant on dry, exposed rocks, boulders on } \\
\text { stony ground, rock ledges, and outcrops. Sometimes encrusted } \\
\text { with epiphytic lichens and mixed with the liverwort } \\
\text { Herzogobryum teres. }\end{array}$ \\
\hline Chorisodontium aciphyllum (Hook. f. and Wils.), Broth & $\begin{array}{l}\text { Turf-forming species occurring almost exclusively on the small } \\
\text { Ardley Island near the Fildes Peninsula. }\end{array}$ \\
\hline Polytrichastrum alpinum (Hedw.) G.L. Sm. & $\begin{array}{l}\text { Small patches associated with Sanionia georgico-uncinata and the } \\
\text { grass Deschampsia antarctica and present in fairly moist places near } \\
\text { ponds. }\end{array}$ \\
\hline Polytrichum strictum Brid. & $\begin{array}{l}\text { Small turfs present, with tall turfs being rare on King George } \\
\text { Island. }\end{array}$ \\
\hline Sanionia uncinata (Hedw.) Loeske & $\begin{array}{l}\text { Dominant species distributed primarily on the lower-level terrain } \\
\text { in both sheltered and open habitats. Commonly associated with } \\
\text { P. alpinum, Bryum spp., and Andreaea spp. }\end{array}$ \\
\hline \multicolumn{2}{|r|}{ 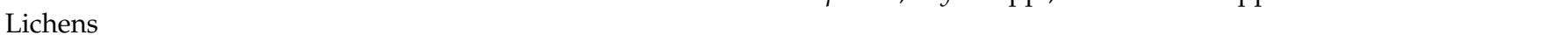 } \\
\hline Cladonia spp. & $\begin{array}{l}\text { Fruticose lichens; commonly associated with turf-forming species } \\
\text { C. aciphyllum and P. strictum in the mixed stands. }\end{array}$ \\
\hline Himantormia lugubris (Hue.) I.M. Lamb & $\begin{array}{l}\text { Fruticose lichens that dominate the lichen community along with } \\
\text { U. antarctica. }\end{array}$ \\
\hline Ochrolechia frigida (Sw.) Lynge & $\begin{array}{l}\text { Commonly associated with } S \text {. uncinata and turf-forming mosses } \\
\text { on dry habitats and gentle slopes, and nearly absent in wet } \\
\text { habitats. }\end{array}$ \\
\hline Placopsis contourtuplicata I.M. Lamb & $\begin{array}{l}\text { Found on dry and fairly exposed gravels of gentle slopes, forming } \\
\text { a rich understory beneath the macrolichens. }\end{array}$ \\
\hline Psoroma spp. & Squamulose lichen, usually associated with mosses. \\
\hline Sphaerophorus globosus (Huds.) Vain. & $\begin{array}{l}\text { Fruticose lichens; usually associated with turf-forming species } \\
\text { C. aciphyllum and P. strictum in mixed stands. }\end{array}$ \\
\hline
\end{tabular}


Table 1. Cont.

\begin{tabular}{|c|c|}
\hline Species & Description \\
\hline Stereocaulon alpinum Laurer & Fruticose lichens; growing in dry and exposed areas. \\
\hline Usnea antarctica Du Rietz & $\begin{array}{l}\text { Fruticose lichens; abundant in most habitats from sheltered to } \\
\text { very exposed and moist to dry, and showing a tendency to occur } \\
\text { in areas with early exposure from snowmelt and in higher } \\
\text { altitude locations. }\end{array}$ \\
\hline \multicolumn{2}{|l|}{ Flowering plants } \\
\hline Colobanthus quitensis (Kunth) Bartl. & $\begin{array}{l}\text { Dicot species observed in sheltered areas facing Marian Cove; } \\
\text { expanded rapidly and primarily associated with patches of } \\
\text { S. uncinata within the Usnea-crustose community. }\end{array}$ \\
\hline Deschampsia antarctica Desv. & $\begin{array}{l}\text { Monocot species mostly growing in the flat areas used by skuas as } \\
\text { resting places around Sejong Point near ponds. Most grass } \\
\text { patches were formed in stable, well-drained areas covered by an } \\
\text { S. uncinata moss carpet. }\end{array}$ \\
\hline \multicolumn{2}{|r|}{ ( } \\
\hline Prasiola crispa (Ligtf.) Kütz. subsp. antarcica (Kütz.) Knebel & $\begin{array}{l}\text { Nitrophilous alga; present around ponds near King Sejong Station } \\
\text { and penguin rookeries with high nitrogen levels. }\end{array}$ \\
\hline
\end{tabular}

\subsection{Spectral Similarity Measures between Library Spectra}

Various similarity metrics have been developed to quantitatively compare reflectance spectra $[33,34]$. Spectral correlation (SC) is a derivative of the Pearson's correlation coefficient (PCC) between the two spectra $\mathbf{x}=\left(x_{1}, x_{2}, \cdots, x_{n}\right)^{\mathrm{T}}$ and $\mathbf{y}=\left(y_{1}, y_{2}, \cdots, y_{n}\right)^{\mathrm{T}}$, according to Equation (1) [35]:

$$
\mathrm{SC}=\frac{n \sum_{1}^{n} x_{i} y_{i}-\sum_{1}^{n} x_{i} \sum_{1}^{n} y_{i}}{\sqrt{\left[n \sum_{1}^{n} x_{i}^{2}-\left(\sum_{1}^{n} x_{i}\right)^{2}\right]\left[n \sum_{1}^{n} y_{j}^{2}-\left(\sum_{1}^{n} y_{j}\right)^{2}\right]}}
$$

where $n$ is the number of spectral bands. SC is relatively simple to compute and considers the overall spectrum shape. The correlation value ranges between -1 and 1 and shows the extent of the linear relationship between the two spectra. SC can be expressed as an angle, applying the arc-cosine.

The spectral angle (SA) is the most widely used spectral similarity index in the analysis of hyperspectral remote sensing imagery. It is similar to the PCC except for the standardization of the data themselves. It measures the angle between two spectral signatures, according to Equation (2) [36]:

$$
\mathrm{SA}=\cos ^{-1}\left(\frac{\sum_{1}^{n} x_{i} y_{i}}{\sqrt{\sum_{1}^{n} x_{i}^{2}} \sqrt{\sum_{1}^{n} y_{i}^{2}}}\right)
$$

SA analysis yields similar results to Euclidean distance (ED) analysis, but the ED is affected by the brightness temperature of the spectra, while the SA and SC are invariant to brightness.

Another common metric is the spectral information divergence (SID) proposed by Chang [33]. The SID exploits spectral band-to-band variability as a random variable and then calculates the discrepancy of probabilistic behaviors between two spectra, whereas the SA simply extracts spectral geometric features. The SID is more effective than the SA at capturing subtle spectral variability [33] and is defined according to Equation (3):

$$
\operatorname{SID}=\sum_{1}^{n} p_{i} \log p_{i} / q_{i}+\sum_{1}^{n} q_{i} \log q_{i} / p_{i}
$$

where $p_{j}=x_{j} / \sum_{1}^{n} x_{i}$ and $q_{j}=y_{j} / \sum_{1}^{n} y_{i}$. Although the SID typically shows better spectral discrimination than other metrics, the number of spectral bands required for calculating the SID limits quantitative comparison. A secondary goal of this research was to com- 
pare the spectral similarities of the 16 vegetation species and decayed moss across three different spectral ranges: VNIR (400-1000 nm), SWIR (1000-2500 nm), and VNIR-SWIR $(400-2500 \mathrm{~nm})$. Thus, the SA is a valuable spectral similarity measure because of its invariability to the number of spectral bands, unlike the SID. SC measurement showed a similar discrimination capability to SA measurement in various comparison studies, and was more effective in spectrally severe overlapping conditions, although it depended on the targets of interest [34,37]. Since there were no significant differences between the SA and SC values in our preliminary experiments, we selected the SA as a primary spectral similarity measure.

The spectral similarity measures only provide information on the similarity or dissimilarity between paired spectra and are insufficient at discriminating between more than two spectral signatures. Field spectra here were measured from homogeneous objects to develop a spectral library; however, most spectra acquired either remotely or from the field were mixtures of more than one signature. To appropriately evaluate spectral discriminant performance, identifying one spectral signature from the other is the foundation for discriminating pixels of highly mixed remote sensing imagery, more indicative of true applications. Relative spectral discriminability entropy (RSDE) provides an overall measure of uncertainty in identifying the mixed signal (d) with respect to a set of spectral signatures (S). $\mathbf{S}$ is defined as $=\left\{\mathbf{s}_{k}\right\}_{k=1}^{K}$, where $K$ is the number of spectra in the set, the mixed spectral signature $(\mathbf{d})$, which is more similar to real remote sensing signals, is modeled in terms of a linear combination of library spectra $\mathbf{s}_{k}$, according to Equation (4):

$$
\mathbf{d}=\sum_{1}^{K} a_{i} \boldsymbol{s}_{i}+\varepsilon
$$

where $a_{i}$ is a scalar value representing the proportion (i.e., fractional abundance) of the field spectrum $s_{i}$, and $\varepsilon$ is the random noise. Two constraints were imposed: (1) nonnegativity $\left(a_{i} \geq 0, \forall a_{i}: 1 \leq i \leq q\right)$ and (2) sum-to-one $\left(\sum_{1}^{K} a_{i}=1\right)$. The spectral discriminability probabilities $p_{\mathbf{d}, \mathbf{S}}(k)$ of all $\mathbf{s}_{k}$ in $\mathbf{S}$ relative to $\mathbf{d}$ can be defined according to Equation (5):

$$
p_{\mathbf{d}, \mathbf{S}}(k)=\frac{\mathrm{SA}\left(\mathbf{d}, \mathbf{s}_{k}\right)}{\sum_{1}^{n} \mathrm{SA}\left(\mathbf{d}, \mathbf{s}_{i}\right)}
$$

This value can be further employed to calculate relative spectral discriminability entropy (RSDE) and to provide an overall measure of uncertainty in identifying the mixed signal (d) with respect to S [33]. RSDE can be calculated according to Equation (6):

$$
\mathrm{RSDE}=-\sum_{k=1}^{n} p_{\mathbf{d}, \mathbf{S}}(k) \log p_{\mathbf{d}, \mathbf{S}}(k)
$$

The lower the RSDE, the higher the chance of correctly identifying $\mathbf{d}$ [33]. To calculate the RSDEs, 100 linear mixtures of library spectra were randomly generated.

\subsection{Generation of Synthetic Images Using Spectral Library}

The enhanced capability of high spectral resolution sensors provides an improved capacity for feature identification compared with that of multispectral sensors. Due to the unavailability of real remote sensing data with corresponding field-surveyed information, synthetic remote sensing images were used as an alternative to evaluate their potential performance in the practical classification/unmixing of vegetation types. First, the fractional abundances of the 16 vegetation species and decayed moss were generated using the Spheric Gaussian Fields method, and synthetic hyperspectral images were reconstructed using the abundances and library spectra. Based on the information on vegetation distribution in the Barton Peninsula acquired from previous field campaigns (2012-2016) [8,38], 16 cases of vegetation composition were defined (Table 2 ). Figure 2 shows an example of a field photo for Case 7. Fractional abundance images $(300 \times 300$ pixels $)$ were created for each case and then combined into a single $1200 \times 1200$ hyperspectral image (Figure 3 ). Figure 4 
illustrates the generated hyperspectral dataset with corresponding class labels, where each pixel is labeled according to the most dominant species based on fractional abundance.

Table 2. Representative vegetation compositions in Barton Peninsula.

\begin{tabular}{ll}
\hline & \\
\hline Case 1 & Polytrichum, Himantormia, Sphaerophorus, Usnea \\
Case 2 & Andreaea, Chorisodontium, Sanionia, Usnea, Colobanthus \\
Case 3 & Polytrichum, Psoroma \\
Case 4 & Sanionia, Placopsis, Usnea \\
Case 5 & Stereocaulon, Usnea \\
Case 6 & Polytrichum, Sanionia, Sphaerophorus, Usnea \\
Case 7 & Andreaea, Chorisodontium, Sanionia, Sphaerophorus, Stereocaulon, Usnea, \\
Case 8 & decayed moss \\
Case 9 & Andreaea, Sanionia, Cladonia, Ochrolechia \\
Case 10 & Sanchampsia, Prasiola \\
Case 11 & Polytrichastrum, Sanionia, Cladonia, Ochrolechia, Usnea \\
Case 12 & Andreaea, Chorisodontium, Himantormia \\
Case 13 & Polytrichastrum, Psoroma, Usnea \\
Case 14 & Sanionia, Ochrolechia, Psoroma \\
Case 15 & Polytrichastrum, Sanionia, Ochrolechia, Usnea \\
Case 16 & Andreaea, Polytrichastrum, Himantormia, Placopsis, Usnea \\
\hline
\end{tabular}

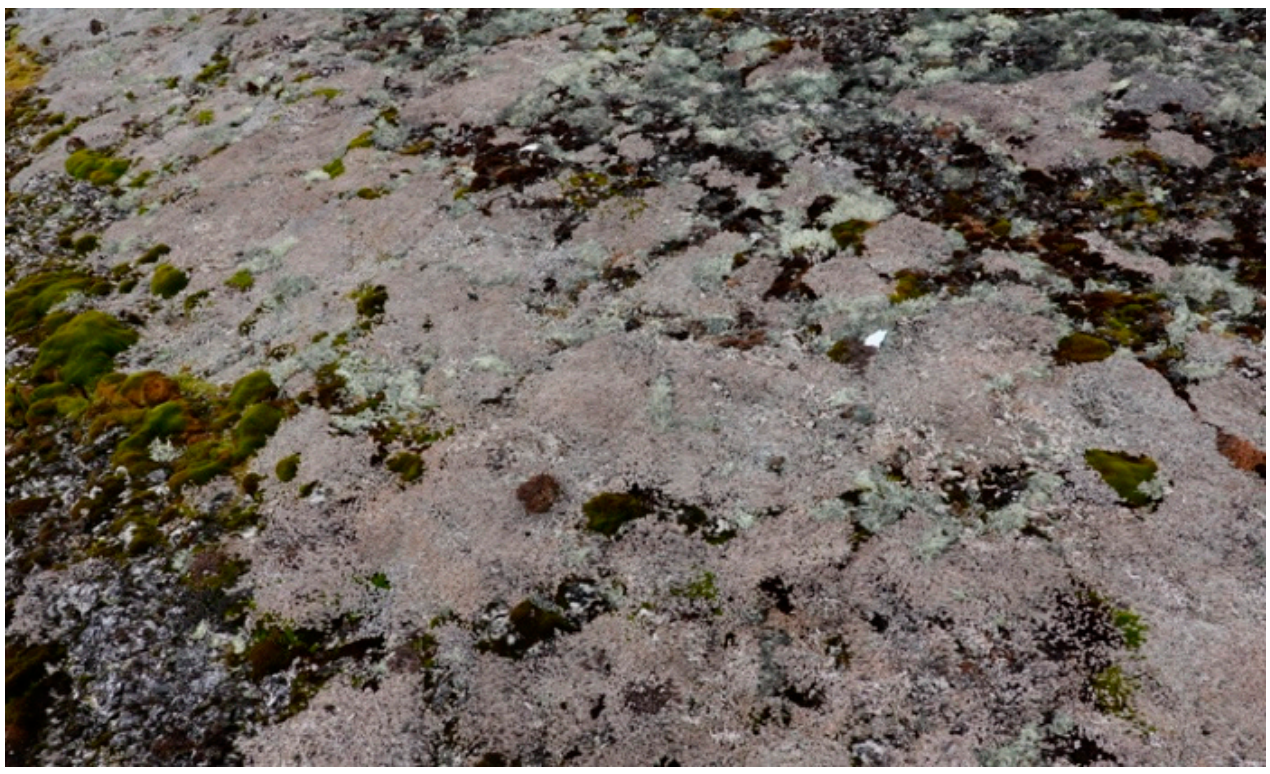

Figure 2. Example of mixed vegetation species for Case 7 (Andreaea, Chorisodontium, Sanionia, Sphaerophorus, Stereocaulon, Usnea, decayed moss). 

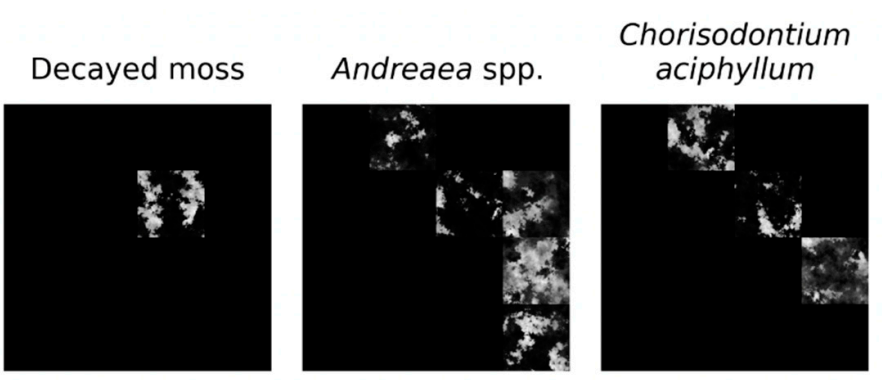

Himantormia

Cladonia spp.

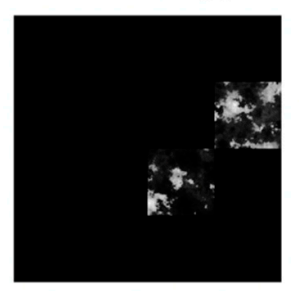

Stereocaulon alpinum

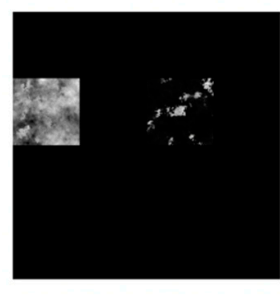
lugubris

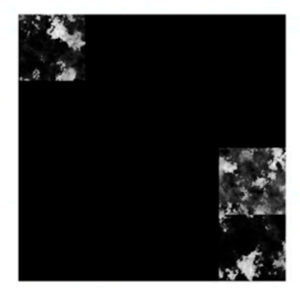

Usnea antarctica

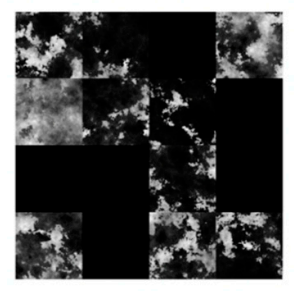

Polytrichastrum alpinum

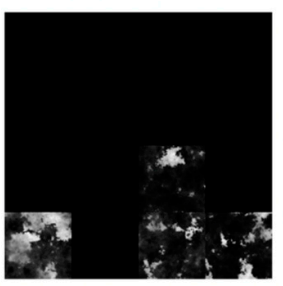

Placopsis contourtuplicata

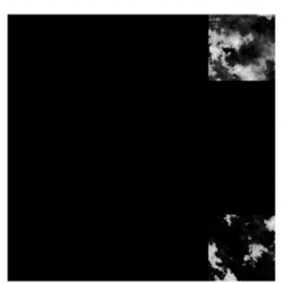

Deschampsia antarctica

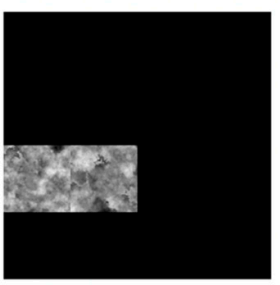

Polytrichum strictum

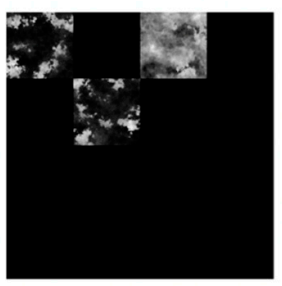

Psoroma spp.

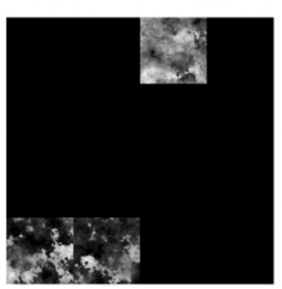

Prasiola crispa

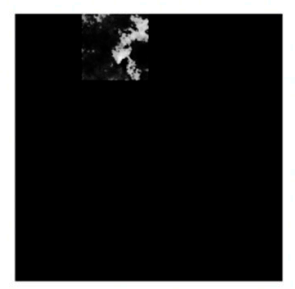

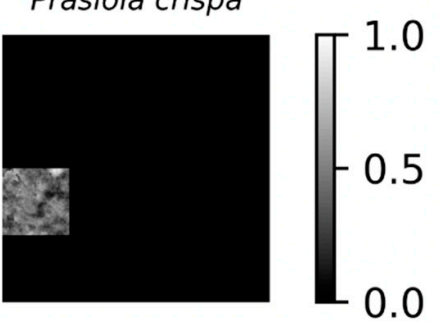

Sanionia

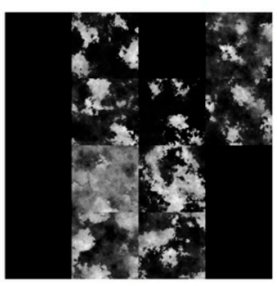

Sphaerophorus globosus

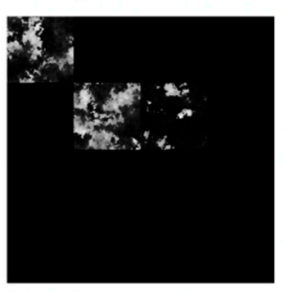

0.0

Figure 3. Simulated fractional abundance images of 16 vegetation species and decayed moss generated by the Spheric Gaussian Fields method.

Synthetic Hyperspectral Image

(R: 1000 nm; G: 1400 nm; B: 2300 nm)

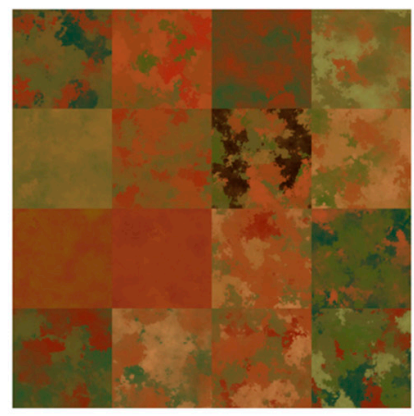

(a)

Vegetation Composition Cases
\begin{tabular}{|l|l|l|l|}
\hline Case 1 & Case 2 & Case 3 & Case 4 \\
\hline Case 5 & Case 6 & Case 7 & Case 8 \\
\hline Case 9 & Case 10 & Case 11 & Case 12 \\
\hline Case 13 & Case 14 & Case 15 & Case 16 \\
\hline
\end{tabular}

(b)

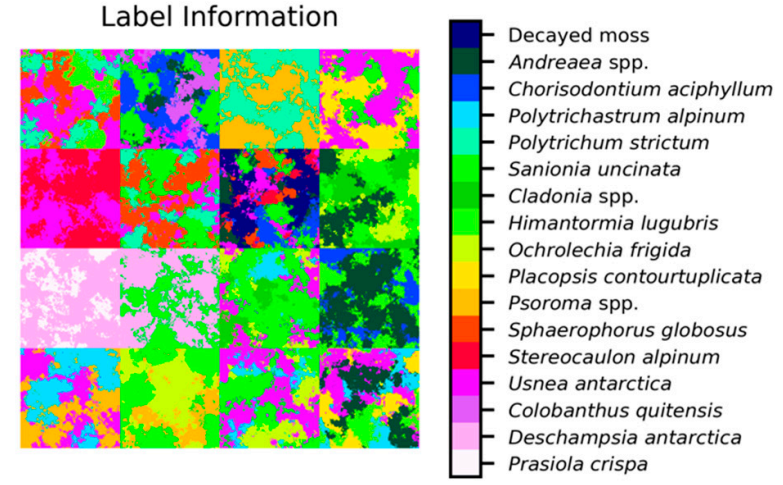

(c)

Figure 4. (a) Generated and combined synthetic hyperspectral images for each (b) vegetation compositional cases as defined in Table 2. (c) Class labels as defined by the most dominant fractional abundances.

The generated synthetic hyperspectral image contained 2101 spectral bands $(400-2500 \mathrm{~nm})$ at a spectral resolution of $1 \mathrm{~nm}$; however, real hyperspectral imaging sensors often have wider 5-10 nm bandwidths. To recreate more realistic hyperspectral images, the $1 \mathrm{~nm}$ spectra were aggregated into $10 \mathrm{~nm}$ bands using the Gaussian spectral response function for each simulated hyperspectral band [39]. Most hyperspectral sensors record reflected radiation from a ground target over either the $400-1000 \mathrm{~nm}$ or the $1000-2500 \mathrm{~nm}$ ranges based on the different types of detector technologies (i.e., silicon detectors are often used for VNIR sensing, while MCT or InSb detectors are common SWIR sensors). Therefore, three hy- 
perspectral sensors were modeled-VNIR (400-1000 nm; 60 bands), SWIR (1000-2500 nm; 150 bands), and VNIR-SWIR (400-2500 nm; 210 bands) - and used to evaluate their vegetation classification and spectral unmixing performance. Additionally, three popular multispectral sensors-WorldView-3, Landsat-8, and IKONOS-were modeled using their spectral response functions (Figure 5). WorldView-3, Landsat-8, and IKONOS have 16, 7, and 4 multispectral bands, respectively. WorldView-3 and Landsat- 8 have 8 and 2 SWIR bands, respectively, whereas IKONOS has no SWIR bands. The center wavelength for each sensor's spectral band is denoted on the x-axes in Figure 5.
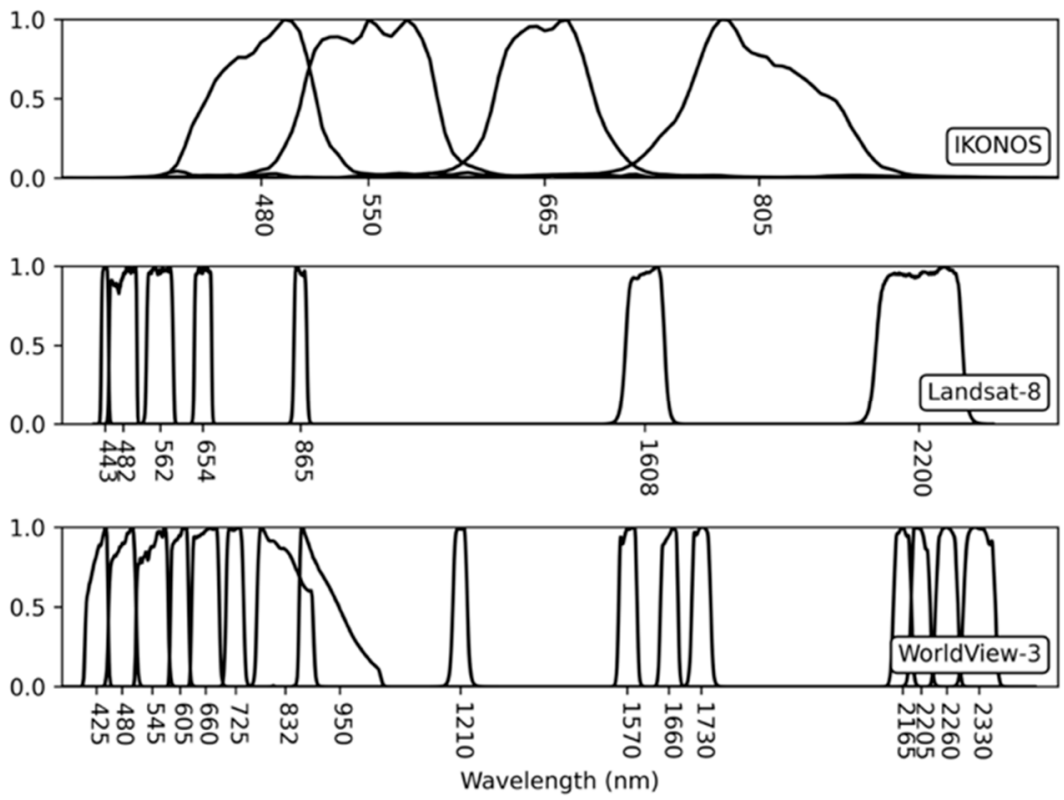

Figure 5. Spectral response functions of popular multispectral remote sensing sensors (IKONOS, Landsat-8, WorldView-3) used to aggregate hyperspectral data into multispectral images. Center wavelength for each band is denoted on the $\mathrm{x}$-axes. The y-axes show relative spectral response.

\subsection{Classification and Spectral Unmixing of Synthetic Images Using Spectral Library}

Classification was carried out using a spectral angle mapper (SAM), which is a physical-based spectral classifier that uses an n-dimensional SA to match pixels to the reference spectra [40]. This classifier is insensitive to illumination and albedo effects and is readily associated with endmember spectra from the spectral library. Each pixel in the synthetic images was assigned to the class that exhibits the smallest SA.

Spectral unmixing was performed to estimate fractional abundances of each species from mixed signals using the least squares solution. To find the fractional abundances $(\alpha)$ that minimize pixel reconstruction error $e=\|\mathrm{r}-\mathrm{M} \alpha\|^{2}$, the least squares solution is $\alpha=\left(M^{T} M\right)^{-1} M^{T} r$, where $r$ is a (mixed) pixel vector and $M$ is endmember matrix (i.e., spectral library). Nonnegativity and sum-to-one constraints were imposed [41].

\section{Results}

\subsection{Spectral Library of Antarctic Vegetation Species}

Figure 6 illustrates the resulting spectral reflectance curves of the representative 16 vegetation species and decayed moss across the $400 \mathrm{~nm}$ to $2500 \mathrm{~nm}$ wavelength range employed in this study. 

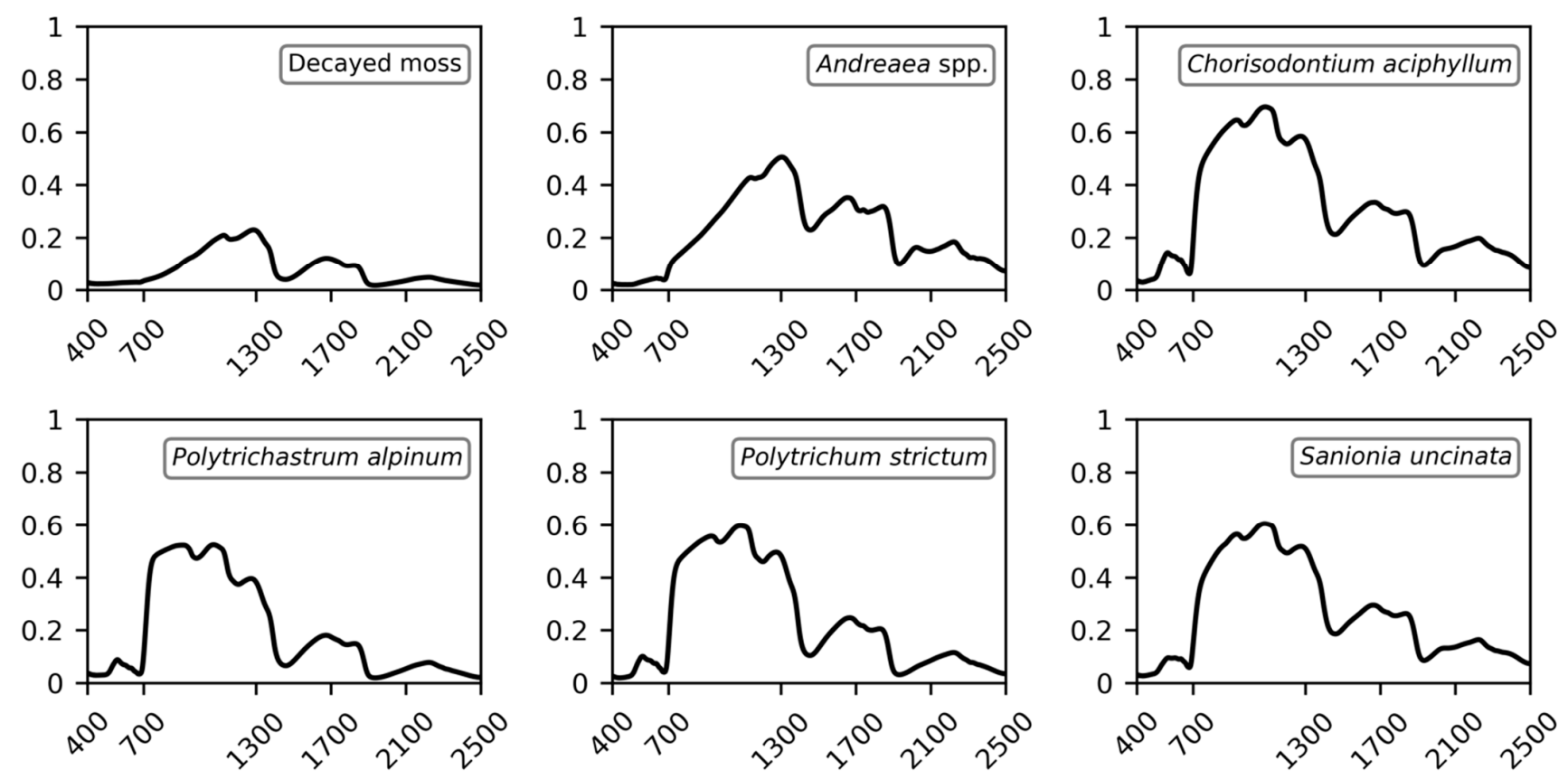

(a)
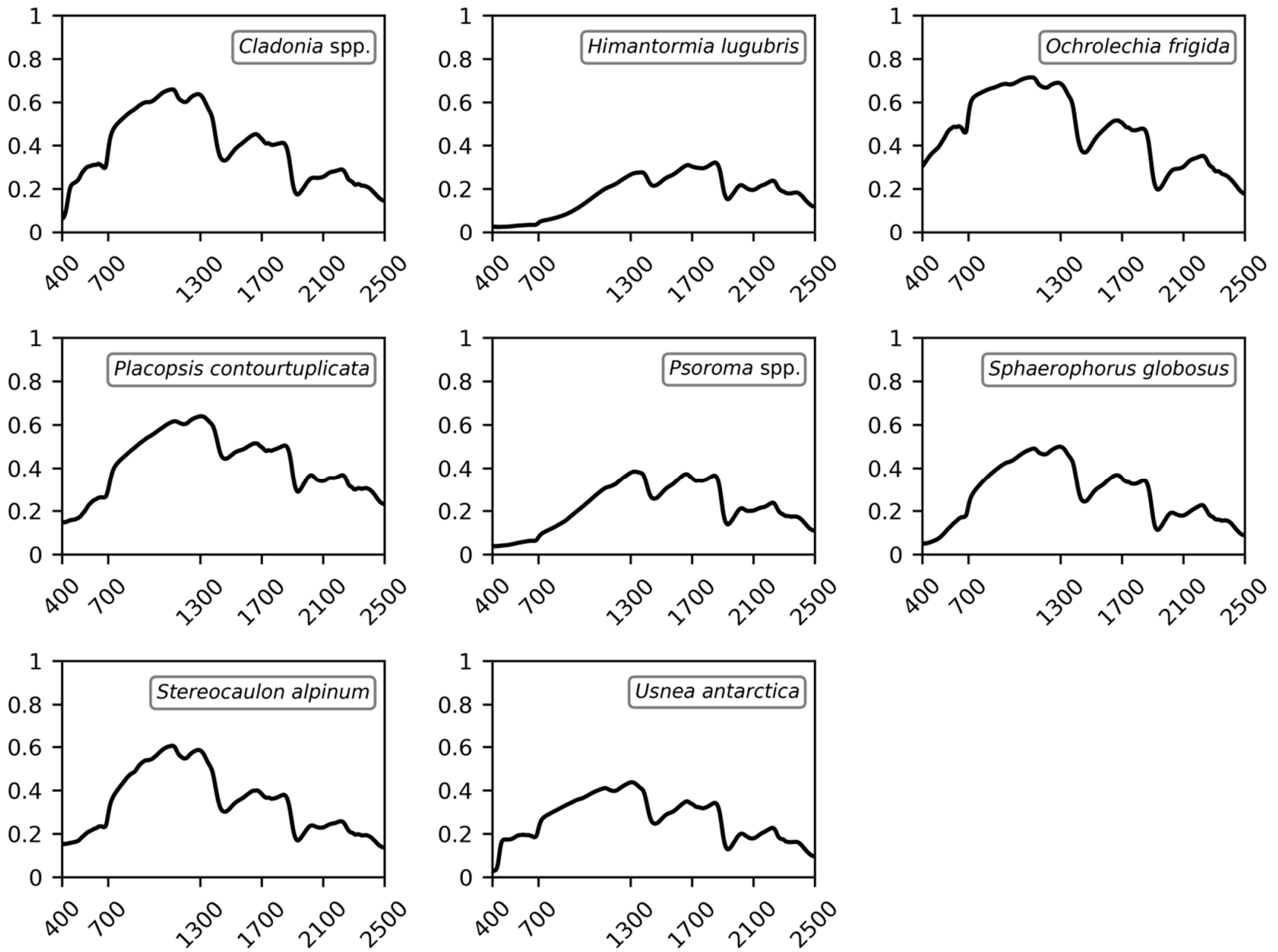

(b)

Figure 6. Cont. 

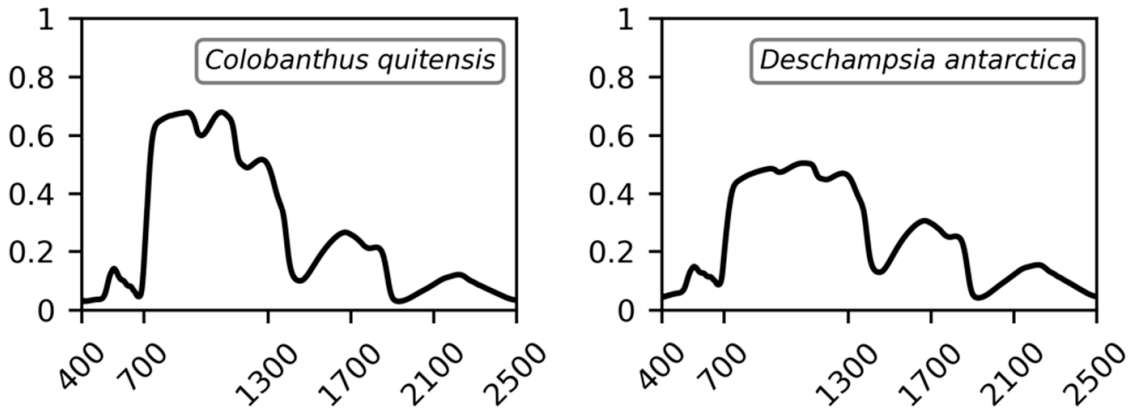

(c)

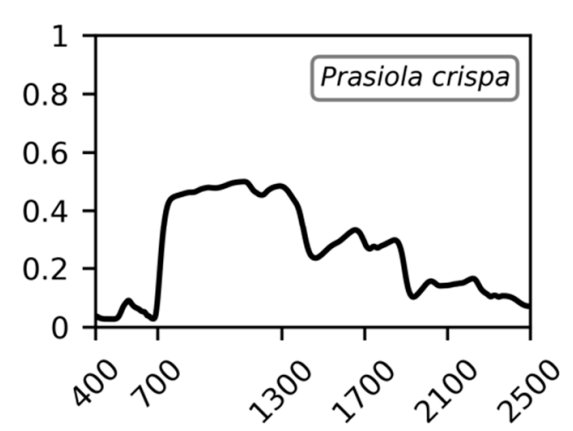

Figure 6. Spectral reflectance curves of 16 representative vegetation species and decayed moss in the Barton Peninsula, for: (a) mosses; (b) lichens; (c) vascular plants and alga group. x-axes show wavelength (nm), and y-axes show reflectance.

The biochemical properties (e.g., cellulose, chlorophyll, lignin, nitrogen, protein, starch, sugar, and water content) of vegetation are closely related to absorption/reflection at a vicinity of specific wavelengths [42-44]. Visible wavelengths are typically related to foliar pigments (mainly chlorophylls). In the NIR region, where there are no strong absorption features except two minor water absorption wavelengths, leaf pigments are transparent, and the magnitude of reflectance is governed by internal cell structure rather than by foliar pigment concentration. SWIR has absorption features related to cellulose, lignin, and water content, and is particularly useful for characterizing the water content in lichens [42-45]. In general, as shown in Figure 6, the analyzed green-leaved vegetation groups, such as most mosses (except Andreaea and decayed moss), vascular plants, and algal species, typically absorbed solar radiation of around $670 \mathrm{~nm}$, corresponding to the chlorophyll absorption maxima of 642-662 nm, and were highly reflective across the green wavelength ranges [46]. For Andreaea, decayed moss, and lichens (Figure 6a,b), chlorophyll absorption was either not observed or was barely detected. Strong absorptions around $1450-1465 \mathrm{~nm}$, attributed to absorption by the hydroxyl $(-\mathrm{OH})$ group, were identified in all species save for the lichens, which exhibited relatively weak features compared with all other groups. As cellulose presence is often associated with a broad absorption feature near $2100 \mathrm{~nm}$, it can be formulated using spectral differences between the adjacent wavelengths near 2000 and $2200 \mathrm{~nm}$ [47]. As seen in Figure 6, such strong absorption patterns were observed in lichens and in an alga, while other groups did not exhibit this feature (save for Andreaea). Additionally, a considerable spectral structure above $2000 \mathrm{~nm}$ was observed in the lichen group, which has been previously documented [48].

As addressed above, the species in each group shared unique spectral characteristics. However, the spectral reflectance of Andreaea differed from the general pattern of other mosses and was closer to that of lichens. The green hump, common to the reflectance spectrum of mosses, was not observed in Andreaea and lichens. The red edge and water absorption near $1200 \mathrm{~nm}$ of Andreaea and lichens were barely detected. The overall spectrum differences between the 400-1300 nm and the 1300-2500 nm regions of Andreaea and lichens were smaller than those of typical mosses. Foliar chemicals such as water, protein, oil, and starch were highly correlated with the spectral response [49]. Reflectance in the $400-1300 \mathrm{~nm}$ range is affected by the scattering of photons within the leaf structure due to changes in the refractive index between liquid water and air within the inter-cellular spaces [42,50]. Dried leaves showed relatively low reflectance values in the $400-1300 \mathrm{~nm}$ range and high values in the 1300-2500 nm range, compared to healthy leaves [51]. Among Antarctic terrestrial mosses, Andreaea is a representative species which inhabits dry areas such as exposed rocks and stony ground [9]. Although there were no measurements of the water content of the Andreaea used in this study, the Antarctic species Andreaea depressinervis had $60 \%$ tissue water content at full turgor compared with Polytrichum alpestre [52], and Andreaea alpina showed the lowest water content of the 15 tested bryophytes, even lower than that of the lichen Cladonia convoluta [53]. Therefore, we assumed that the unique 
spectral characteristics of Andreaea were due to the low water content, which is a typical characteristic of lichens inhabiting dry environments [42]. However, investigations of the ultra-structure or foliar chemical contents of Andreaea, which were absent in this study, may explain these characteristics.

Although the above standard features were identified through a combination of visual interpretation and general knowledge, analyses were limited to providing quantitative separability for species identification via remote sensing imagery.

\subsection{Spectral Discrimination of Antarctic Vegetation}

SAs were first calculated between two vegetation species in the VNIR, SWIR, and VNIR-SWIR spectral ranges (Figure 7). Figure 7a shows paired SA differences in the VNIR region, while Figure $7 \mathrm{~b}, \mathrm{c}$ show those in the SWIR and VNIR-SWIR regions, respectively, with colors denoting the SA improvements over the VNIR range. Table 3 summarizes the average SAs of each species by wavelength range. Inter-species separability was improved in 78 out of 136 cases when including SWIR wavelengths, whereas decreased discriminative ability was seen in 58 combinations. Nine species (Chorisodontium, Polytrichastrum, Polytrichum, Sanionia, Himantormia, Placopsis, Psoroma, Colobanthus, and Deschampsia) yielded increased average interspecies separability, while eight species showed a decrease. For example, decayed moss and Andreaea, often dark in color, exhibited a 0.1694 SA difference in the VNIR region, but the SA significantly increased to 0.2761 in the SWIR region, indicating that much of the spectral information of these two subjects is contained within the SWIR wavelengths. Alternatively, some mosses such as Chorisodontium, Polytrichastrum, Polytrichum, and Sanionia, which are distinguishable from decayed mosses by visual analysis in the field, had smaller SA differences in the SWIR region than across the VNIR wavelengths. Himantormia also displayed better separability when including SWIR reflectance. No distinguishable absorption feature around the 1100-1200 nm wavelength was found in the spectral reflectance curve of Himantormia, unlike in that of other species, and the brightness of its SWIR bands was relatively high compared with that of its VNIR bands, potentially translating into the enhanced discrimination of Himantormia in the SWIR region. The separability of Ochrolechia in the SWIR region was deteriorated compared with that in the VNIR region. In particular, the most significant decrease in the average relative SA with respect to the VNIR region $(\sim 76 \%)$ was observed in this species. It should be noted that Ochrolechia, which showed high reflectance values in the VNIR region, is readily distinguishable from other dark or green species, and it had the largest average separability (0.3637) of all species in the VNIR range. The VNIR range inter-species separability between Chorisodontium, Colobanthus, Deschampsia, and Prasiola was complicated by a shared high peak in the green band and showed dramatically increased reflectance values around the $700 \mathrm{~nm}$ wavelength; however, the separability significantly improved with the inclusion of the SWIR wavelengths.

When incorporating reflectance values obtained across the VNIR-SWIR range, the SAs of 98 paired species showed improvements, while those of 38 cases slightly decreased, compared with those obtained across the VNIR range alone (i.e., the blueness of Figure 7c). Although 38 combinations yielded decreased separability compared with that seen in the VNIR range, the pairs still showed improved discrimination than that seen across the SWIR wavelengths alone. Overall, the average separability of all species, except Ochrolechia, was improved, although its combined average SA (0.3321) still maintained relatively good separability compared with that of the other species (Table 3 ).

To evaluate the overall separability of highly mixed signals, the calculated RSDEs of the VNIR, SWIR, and VNIR-SWIR ranges were 2.7723, 2.2262, and 2.0693, respectively. Accordingly, employing the full-spectrum range was most effective since it provided more spectral information than using either the VNIR or SWIR ranges alone; however, a lower RSDE value for the SWIR wavelengths than for the VNIR indicated that the former were more statistically useful for identifying the 16 vegetation species and decayed moss from 
the mixed signals. As an invariant SA was used as a similarity index, the number of bands in each spectral range did not affect either the SA or the RSDE.

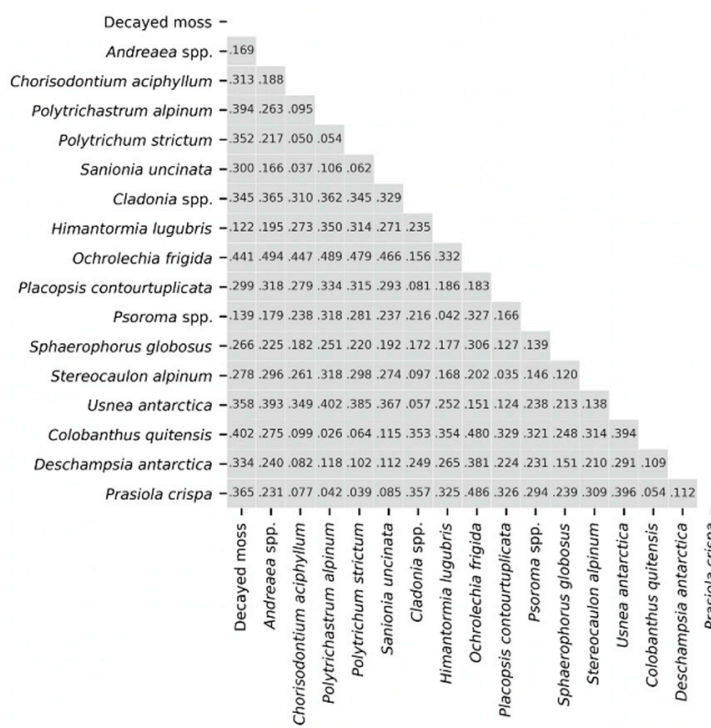

(a)

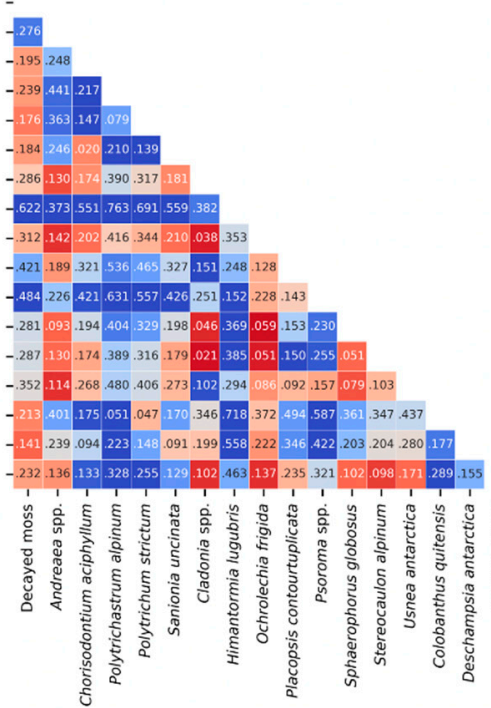

(b)

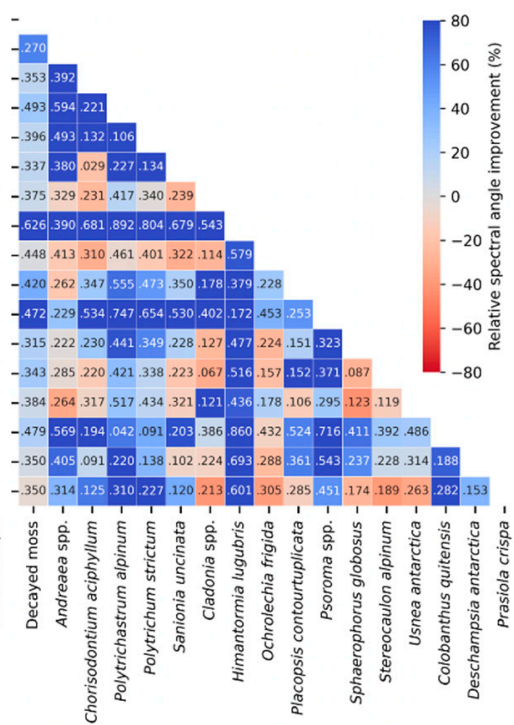

(c)

Figure 7. Spectral angle comparisons of 16 vegetation species and decayed moss for the (a) VNIR, 400-1000 nm; (b) SWIR, 1000-2500 nm; and (c) VNIR-SWIR 400-2500 nm ranges. Relative spectral angle improvements with respect to the 400-1000 nm range are color-coded (positive improvements, blue; negative improvements, red).

Table 3. Average spectral angles of 16 vegetation species and decayed moss according to the VNIR, SWIR, and VNIR-SWIR ranges (note: the underlined values indicate better separability between the VNIR and SWIR ranges, and the values in bold are the best separability).

\begin{tabular}{cccc}
\hline Species & VNIR & SWIR & VNIR-SWIR \\
\hline Decayed moss & $\underline{0.3047}$ & 0.2937 & $\mathbf{0 . 4 0 0 6}$ \\
Andreaea & $\underline{0.2634}$ & 0.2342 & $\mathbf{0 . 3 6 3 2}$ \\
Chorisodontium & 0.2049 & $\underline{0.2208}$ & $\mathbf{0 . 2 7 5 4}$ \\
Polytrichastrum & 0.2450 & $\underline{0.3623}$ & $\mathbf{0 . 4 1 6 4}$ \\
Polytrichum & 0.2233 & $\underline{0.2214}$ & $\mathbf{0 . 3 4 4 3}$ \\
Sanionia & 0.2131 & 0.1947 & $\mathbf{0 . 2 7 6 5}$ \\
Cladonia & $\underline{0.2519}$ & $\underline{0.4674}$ & $\mathbf{0 . 2 6 9 1}$ \\
Himantormia & 0.2412 & 0.2062 & $\mathbf{0 . 5 8 3 0}$ \\
Ochrolechia & $\underline{\mathbf{0 . 3 6 3 7}}$ & $\underline{0.2749}$ & 0.3321 \\
Placopsis & 0.2262 & $\underline{0.3432}$ & $\mathbf{0 . 3 1 4 2}$ \\
Psoroma & 0.2194 & 0.1971 & $\mathbf{0 . 4 4 6 5}$ \\
Sphaerophorus & $\underline{0.2017}$ & 0.1962 & $\mathbf{0 . 2 5 7 4}$ \\
Stereocaulon & $\underline{0.2164}$ & 0.2309 & $\mathbf{0 . 2 5 6 7}$ \\
Usnea & $\underline{0.2817}$ & $\underline{0.3241}$ & $\mathbf{0 . 2 9 2 4}$ \\
Colobanthus & 0.2460 & $\underline{0.2314}$ & $\mathbf{0 . 3 9 1 0}$ \\
Deschampsia & 0.2007 & 0.2054 & $\mathbf{0 . 2 8 3 5}$ \\
Prasiola & $\underline{0.2335}$ & & $\mathbf{0 . 2 7 2 6}$ \\
\hline
\end{tabular}

\subsection{Classification and Spectral Unmixing Using Synthetic Remote Sensing Images}

Alongside the spectral similarity of paired spectra and the overall discriminating performance of mixed spectra tested above, the present analysis was designed to investigate the discriminability and quantification of Antarctic vegetation in practical remote sensing images using synthetic hyperspectral and multispectral imagery. 


\subsubsection{Classification of Vegetation Species}

As described in Sections 2.4 and 2.5, three synthetic hyperspectral images and three multispectral images were classified using the library spectra and a SAM. Experiments were conducted across all synthetic image data to investigate the performance related to spectral information, although the spatial resolution of each sensor was not considered. The overall accuracy can be seen in Table 4 for all 17 classes as well as for the most dominant classes, as defined by the quantitative approach through field campaigns [38]. Table 5 shows the spatial coverage of the five dominant species. Usnea maintains the largest spatial population in the Barton Peninsula, covering $23 \%$ of the area. Psoroma, Ochrolechia, Sanionia, and Andreaea accounted for $\sim 15,12,10$, and $9 \%$ of the area, respectively. Cumulatively, these five species made up more than $72 \%$ of the total vegetation coverage, with the three most dominant species accounting for approximately $50 \%$.

Table 4. Comparison of the overall accuracy according to sensor type and the number of classes (note: 5 and 3 species refer to the most dominant 5 and 3 species, respectively).

\begin{tabular}{ccccccc}
\hline & \multicolumn{3}{c}{ Hyperspectral } & \multicolumn{3}{c}{ Multispectral } \\
\cline { 2 - 7 } & VNIR & SWIR & VNIR-SWIR & IKONOS & Landsat-8 & WorldView-3 \\
\hline 17 classes & $77.23 \%$ & $89.15 \%$ & $92.15 \%$ & $20.33 \%$ & $35.31 \%$ & $46.42 \%$ \\
5 species & $92.24 \%$ & $93.18 \%$ & $98.13 \%$ & $69.24 \%$ & $71.12 \%$ & $84.30 \%$ \\
3 species & $99.04 \%$ & $94.17 \%$ & $98.61 \%$ & $88.50 \%$ & $87.92 \%$ & $94.17 \%$ \\
\hline
\end{tabular}

Table 5. Spatial coverage of the five dominant species from field surveys in the Barton Peninsula.

\begin{tabular}{cccccc}
\hline & Usnea & Psoroma & Ochrolechia & Sanionia & Andreaea \\
\hline Coverage & $23.51 \%$ & $15.74 \%$ & $12.55 \%$ & $10.66 \%$ & $9.86 \%$ \\
Cumulative coverage & - & $39.26 \%$ & $51.80 \%$ & $62.46 \%$ & $72.31 \%$ \\
\hline
\end{tabular}

For the complete 17-class experiments (Table 4), the most accurate analyses were obtained using the VNIR-SWIR ranges of the hyperspectral data. Similar to the results of the inter-class separability tests, the SWIR spectra were more useful for classifying the Antarctic vegetation than the VNIR spectra. Figure 8 illustrates the classified vegetation maps of all the hyperspectral and multispectral datasets. None of the multispectral sensors more accurately classified vegetation species compared with the hyperspectral sensors. Similar to the results of the statistical comparisons, multispectral data showed a large number of misclassified pixels, whereas hyperspectral data showed much greater agreement with the label data; however, some differences were observed between the three hyperspectral datasets. For example, in Case 5, consisting of Stereocaulon and Usnea, many Stereocaulon (red) pixels were classified as Placopsis (yellow) in the VNIR image, while the SWIR and VNIR-SWIR datasets had them correctly classified. As indicated by the spectral reflectance curves of Placopsis and Stereocaulon in Figure $6 \mathrm{~b}$ and the 0.0345 SA value in Figure 7a, these two species share similar spectral characteristics across the VNIR range, resulting in the occurrence of many misclassified pixels in the images without SWIR data. Case 9 consisted of Deschampsia and Prasiola and discriminating between these two species was difficult across the VNIR range (Figure 8). Many pixels were classified as Polytrichastrum (light blue) in the VNIR image because Polytrichastrum and the flowering plants showed similar spectral curves (Figure 6a,c). The paired SAs of PolytrichastrumDeschampsia, Polytrichastrum-Prasiola, and Deschampsia-Prasiola across the VNIR range were $0.1176,0.0417$, and 0.1115 , respectively (Figure 7a); however, data from across the SWIR and VNIR-SWIR ranges were able to successfully distinguish these species. 


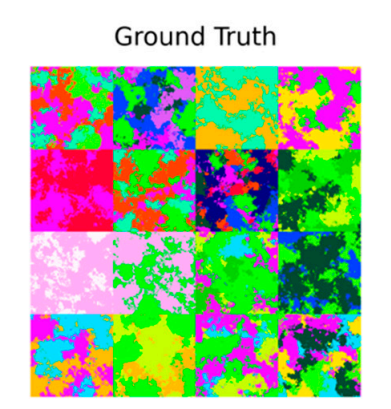

Vegetation Composition Cases

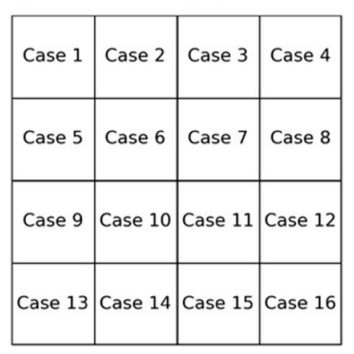

VNIR

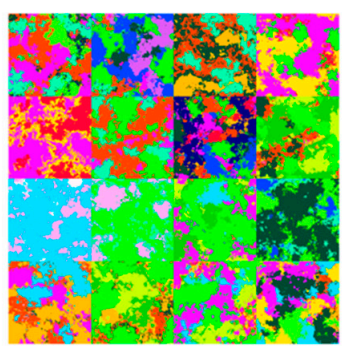

WorldView-3

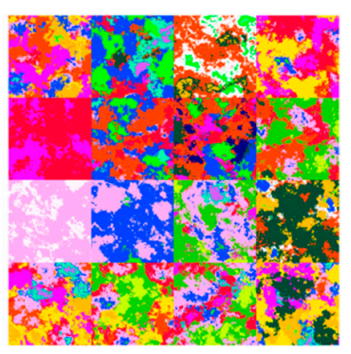

SWIR

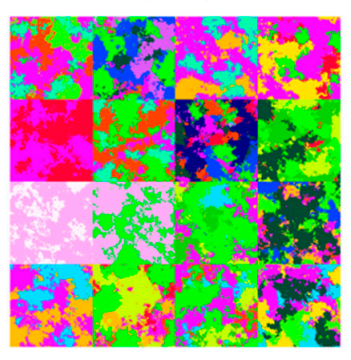

Landsat-8

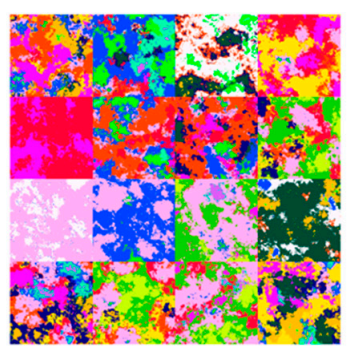

VNIR-SWIR

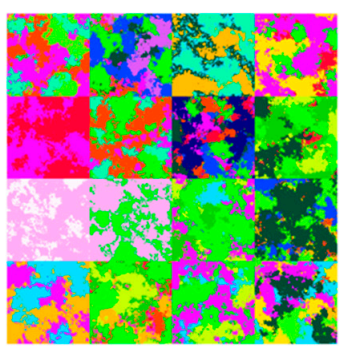

IKONOS

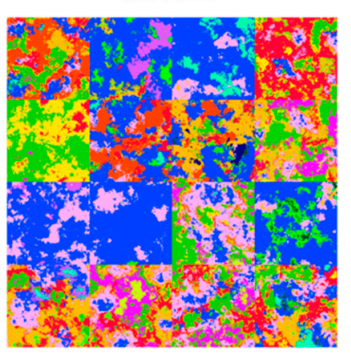

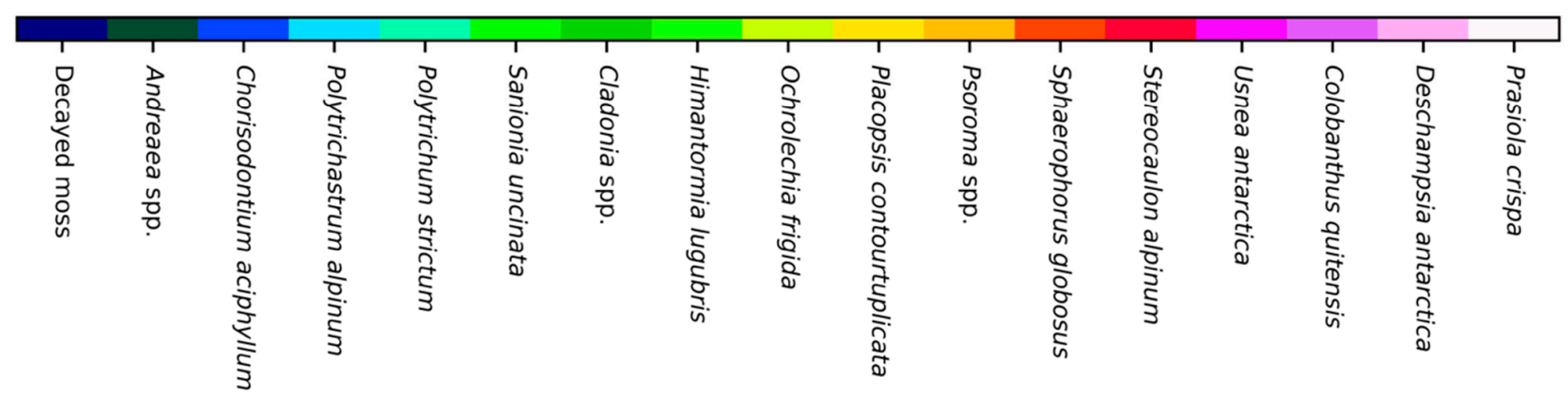

Figure 8. Classified vegetation species maps across different wavelengths and sensors, generated by spectral angle mappers according to the developed spectral library.

In five-dominant class experiments, however, less informative multispectral sensors showed significant statistical improvements to 17-class analyses. Moreover, multispectral sensors could correctly identify the three most dominant classes with $\sim 90 \%$ accuracy. Overall, the sensors with more spectral bands across the SWIR range showed improved classification accuracies (i.e., Landsat-8 had two SWIR bands, WorldView-3 had eight, while no SWIR bands were present in IKONOS; Table 4), aligning with the finding that SWIR wavelengths contain more meaningful information for the characterization of Antarctic vegetation.

\subsubsection{Spectral Unmixing of Vegetation Species}

The spatial resolutions of each sensor employed were the same in previous classification experiments; however, spatial resolution is a foundational distinguishing characteristic in remote sensing analyses. Let $1200 \times 1200$ synthetic hyperspectral images be $0.1 \mathrm{~m}$ of the spatial resolution from UAV platforms. If the same area is captured using $4 \mathrm{~m}$ and $30 \mathrm{~m}$ spatial resolution sensors, the resulting image sizes are $30 \times 30$ and $4 \times 4$, respectively, which may not be acceptable for successful image classification. In lower spatial resolution images covering the same area, most pixels are a mixture of more than one vegetation species. As an alternative to single object classification, spectral unmixing decomposes mixed pixels into a collection of individual pure spectral signatures at the sub-pixel level and enables more quantitative analyses than standard image classification [40]. In this experiment, pixels in simulated hyperspectral and multispectral images taken by satellites and UAVs were decomposed in a manner similar to that used in the classification experi- 
ments, but considering spatial resolution. The resolutions and image sizes of the simulated images for the spectral unmixing tasks are listed in Table 6.

Table 6. Spatial/spectral resolution, image size, and band number of simulated remote sensing images according to platform and sensor types.

\begin{tabular}{ccccc}
\hline Platform & Sensor & Spatial Resolution & Image Size & Spectral Bands \\
\hline \multirow{2}{*}{ UAV } & Hyperspectral & $0.1 \mathrm{~m}$ & $1200 \times 1200$ & 210 \\
& Multispectral & $0.1 \mathrm{~m}$ & $1200 \times 1200$ & 4 \\
\hline \multirow{3}{*}{ Satellite } & WorldView-3 & $4 \mathrm{~m}$ & $30 \times 30$ & 16 \\
& IKONOS & $4 \mathrm{~m}$ & $30 \times 30$ & 4 \\
& Hyperion & $30 \mathrm{~m}$ & $4 \times 4$ & 220 \\
& Landsat-8 & $30 \mathrm{~m}$ & $4 \times 4$ & 7 \\
\hline
\end{tabular}

Table 7 lists the true abundances that were used to generate the synthetic imagery and the reconstructed abundances from the unmixing of simulated sensor imagery. These reconstructed abundances from the UAV-based hyperspectral images were nearly identical to the true abundance values. Small UAVs often mount four-band multispectral sensors (RGB + NIR) to acquire very high spatial resolution imagery. However, as shown in Table 7, significant differences between the reconstructed abundances, estimated from multispectral sensors mounted on the UAVs, and the true coverage indicate that less spectral information is detrimental to accurately quantifying vegetation species, unless that information is obtained at a very high spatial resolution. In $30 \times 30$ images, 16 bands of WorldView-3 successfully quantified vegetation species coverage, whereas the four bands of IKONOS failed to reconstruct the distribution. The simulated Hyperion image, generated by one of the most widely employed spaceborne hyperspectral sensors, consisted of only $4 \times 4$ pixels but most accurately depicted abundances among all satellite-based sensor images; however, the images may not be able useful for creating thematic maps. Landsat- 8 images, $4 \times 4$ in size with a $30 \mathrm{~m}$ spatial resolution, yielded better abundance estimations than IKONOS images with $4 \mathrm{~m}$ resolution, but they still did not quantify some vegetation covers accurately. Naturally, high spatial resolution imagery is necessary for qualitative mapping by visually analyzing study areas; however, Hyperion's successful abundance estimates indicated that rich spectral information is also essential to quantitatively analyze the environmental cover. Although the present experiment was derived using a simple linear mixture model and pure endmember spectra, notably rare in practice, it effectively demonstrated the importance of spectral information.

Table 7. Comparisons of reconstructed fractional abundances of 16 vegetation species and decayed moss from linear spectral unmixing, according to types of remote sensing data.

\begin{tabular}{|c|c|c|c|c|c|c|c|}
\hline \multirow{2}{*}{ Classes } & \multirow{2}{*}{ Ground Truth } & \multicolumn{2}{|c|}{ UAV } & \multicolumn{4}{|c|}{ Satellite } \\
\hline & & Hyperspectral & Multispectral & WorldView-3 & IKONOS & Hyperion & Landsat- 8 \\
\hline Decayed moss & 39,285 & 39,285 & 741 & 40,876 & 0 & 39,157 & 14,444 \\
\hline Andreaea & 103,415 & 103,415 & 24,347 & 104,823 & 14,252 & 103,091 & 100,432 \\
\hline Chorisodontium & 60,772 & 60,772 & 2061 & 60,109 & 2208 & 62,233 & 50,703 \\
\hline Polytrichastrum & 19,799 & 19,799 & 149,167 & 21,141 & 176,967 & 20,575 & 186,550 \\
\hline Polytrichum & 25,698 & 25,702 & 284,107 & 27,493 & 331,520 & 27,265 & 29,093 \\
\hline Sanionia & 100,522 & 100,522 & 51,224 & 98,278 & 40,534 & 101,385 & 51,045 \\
\hline Cladonia & 65,250 & 65,251 & 48,086 & 67,615 & 44,203 & 65,208 & 43,317 \\
\hline Himantormia & 84,828 & 84,828 & 165,020 & 86,029 & 185,792 & 84,721 & 76,151 \\
\hline Ochrolechia & 46,887 & 46,887 & 27,328 & 47,447 & 17,764 & 47,561 & 91,286 \\
\hline Placopsis & 72,340 & 72,341 & 58,475 & 73,203 & 43,237 & 70,976 & 135,734 \\
\hline Psoroma & 85,348 & 85,347 & 533 & 84,039 & 448 & 84,009 & 0 \\
\hline Sphaerophorus & 38,781 & 38,781 & 38,781 & 40,990 & 28,444 & 39,904 & 51,535 \\
\hline Stereocaulon & 100,468 & 100,468 & 0 & 97,765 & 0 & 99,320 & 142,703 \\
\hline Usnea & 238,132 & 238,132 & 302,951 & 236,002 & 307,771 & 236,433 & 36,420 \\
\hline Colobanthus & 59,759 & 59,759 & 119,294 & 59,855 & 127,283 & 60,406 & 137,901 \\
\hline Deschampsia & 55,930 & 55,929 & 52,848 & 56,206 & 45,741 & 55,618 & 26,675 \\
\hline Prasiola & 242,783 & 242,782 & 115,037 & 238,127 & 73,836 & 242,138 & 266,011 \\
\hline
\end{tabular}




\section{Discussion}

Research on vegetation species classification using remote sensing data is currently popular. However, as we discussed in the introduction, this research has been conducted based on limited field-survey information or image-driven spectral information due to the unavailability of spectral libraries for Antarctic vegetation species. We believe that the spectral library developed in this study can be used as ground truth and can assist in understanding remote sensing data in various disciplines. Along with the development of the spectral library, two research questions were raised in this study: (1) which spectral ranges are required to effectively analyze Antarctic vegetation in remote sensing? (2) which sensor is appropriate for classifying or quantifying vegetation species? To address these questions, we conducted experiments to compare interspecies separability and performed image classification/unmixing using simulated remote sensing imagery according to spectral resolution.

First, whereas only visible and NIR wavelengths have been investigated for the Antarctic vegetation in previous research [25], this study explored a full spectral range and revealed the importance of using SWIR wavelengths for accurately identifying various vegetation classes. The VNIR range could generally explain cell structure and leaf pigments better than longer wavelengths; however, vegetation in cold regions may have relatively weaker spectral signals corresponding to this information and may present stronger wateror biochemical-related information in the SWIR region, compared with vegetation in temperate latitudes. This was tested using individual spectra and simulated image data discussed in Section 3. Particularly, the identification of Deschampsia and Prasiola, which has previously been reported as a challenge when using data from across the VNIR range [25], was improved at $1000-2500 \mathrm{~nm}$.

With respect to the second question: the synthetic images in Section 3.3 were generated using library spectra to model popular remote sensing images, including multi- and hyperspectral sensors, owing to the unavailability of real image data for the study area. SAM-based classification and linear unmixing methods were applied to the generated images to investigate which sensor was optimal for analyzing vegetation distributions in practical applications. These experiments represented ideal scenarios since simulated images of known library spectra, using assumed linear mixture models and the ground truth, were used. With true remote sensing imagery, the resulting accuracy will be lower, as it will be difficult to associate the library spectra with the images owing to different data acquisition conditions. However, under the same experimental conditions, hyperspectral data significantly outperformed multispectral sensor data in identifying and quantifying Antarctic vegetation. In particular, these results also indicate that spectral information from the SWIR wavelengths was more effective than that from the VNIR. However, it is worth noting that multispectral sensors showed reasonable classification performance for several dominant species. Particularly, multispectral sensors with more SWIR range bands showed better results than those with fewer bands. Therefore, considering the difficulty in acquiring high-quality hyperspectral data, the purpose of the application, and the vegetation compositions of the study area, the selection of proper remote sensing data would be important.

Although we demonstrated the potential performance of several sensors to analyze vegetation species according to their spectral resolutions, it is difficult to conclude which species are clearly separated by which sensor or wavelength region. For example, in Case 12, consisting of Andreaea, Chorisodontium and Himantormia, as shown in Figure 8, the VNIR region images showed better classification results than the SWIR and VNIR-SWIR region images. Some Andreaea and Himantormia pixels in the SWIR and VNIR-SWIR region images were misclassified to Usnea and Psoroma, respectively. However, the Andreaea species in Cases 2, 7, and 16 were successfully identified in both the VNIR and SWIR range data, with even WorldView-3 and Landsat-8 classifying them relatively well, compared with the other species. Himantormia in Cases 1 and 16 were also correctly classified using the VNIR and SWIR datasets. This should indicate that while the spectral resolution of the sensor is 
crucial, types of species that consist of image pixels are also important for determining the sensor's classification and unmixing performance.

Conventional surveys assessing vegetation cover over quadrants in the Barton Peninsula have been conducted for several years across sparse locations. However, these surveys are costly, and their findings do not adequately quantify the overall vegetation cover. Recent advances in sensor technologies have facilitated the development of miniaturized hyperspectral sensors for drones. In future work, the spectral library created here, and hyperspectral UAV data should be incorporated to generate detailed vegetation maps of the entire Barton Peninsula, as an alternative to conducting physically intensive field surveys. Satellite remote sensing data, including a new hyperspectral sensor PRISMA (PRecursore IperSpettrale della Missione Applicativa) [54] or high-resolution multispectral data, should also be investigated using the spectral library, based on research goals and sensor performance. In addition, intraspecies spectral variations exist according to color, shape, and environmental conditions. As the spectral library was created with multiple measurements for each species and was temporally distanced from rain or snow events, the spectra used should be considered the most representative signals of the species. However, developing a more detailed library that factors in environmental and physiological conditions is a worthwhile alternative to the potentially destructive contact that currently occurs during the characterization of vegetation.

\section{Conclusions}

The present study developed a spectral library of 16 major vegetation species and decayed moss in the Barton Peninsula of King George Island, Antarctica, and investigated the interspecies separability and analysis performance using simulated remote sensing imagery. We demonstrated that full-range spectral information was the most effective; however, SWIR range information contributed to better discrimination of the representative vegetation species in the study area than VNIR range information. With respect to practical application using the spectral library and remote sensing data, hyperspectral data are ideal for analyzing vegetation species qualitatively and quantitatively. However, multispectral data with more SWIR range bands showed good performance for several dominant species.

Author Contributions: Conceptualization, J.C., H.L. and S.G.H.; methodology, J.C. and H.L.; formal analysis, J.C., H.L. and S.G.H.; writing — original draft preparation, J.C.; writing-review and editing, H.L., S.G.H. and H.-C.K.; supervision, H.L.; funding acquisition, H.L. All authors have read and agreed to the published version of the manuscript.

Funding: This research was funded by the Korea Polar Research Institute (grant number PE21130).

Data Availability Statement: The spectral library is available from the authors or the Korea Polar Data Center (https:/ / kpdc.kopri.re.kr) upon reasonable request.

Acknowledgments: We would like to acknowledge Mi Young Byun and Sung Mi Cho for their assistance in identifying the vegetation species during the field campaigns.

Conflicts of Interest: The authors declare no conflict of interest.

\section{References}

1. Grimm, N.B.; Chapin, F.S., III; Bierwagen, B.; Gonzalez, P.; Groffman, P.M.; Luo, Y.; Melton, F.; Nadelhoffer, K.; Pairis, A.; Raymond, P.A. The impacts of climate change on ecosystem structure and function. Front. Ecol. Environ. 2013, 11, 474-482. [CrossRef]

2. Longton, R.E. Biology of Polar Bryophytes and Lichens; CUP Archive: Cambridge, UK, 1988.

3. Smith, R.L. Signy Island as a Paradigm of Biological and Environmental Change in Antarctic Terrestrial Ecosystems. In Antarctic Ecosystems: Ecological Change and Conservation. SCAR Symposium on Antarctic Biology; Kerry, K.R., Hempel, G., Eds.; Springer: Berlin, Germany, 1990; pp. 32-50.

4. Kennedy, A.D. Antarctic terrestrial ecosystem response to global environmental change. Ann. Rev. Ecol. Syst. 1995, 26, 683-704. [CrossRef]

5. Convey, P. Terrestrial biodiversity in Antarctica-Recent advances and future challenges. Polar Sci. 2010, 4, 135-147. [CrossRef] 
6. Turner, J.; Barrand, N.E.; Bracegirdle, T.J.; Convey, P.; Hodgson, D.A.; Jarvis, M.; Jenkins, A.; Marshall, G.; Meredith, M.P.; Roscoe, H.; et al. Antarctic climate change and the environment: An update. Polar Rec. 2014, 50, 237-259. [CrossRef]

7. Domack, E.; Leventer, A.; Burnett, A.; Bindschadler, R.; Convey, P.; Kirby, M. Antarctic Peninsula Climate Variability: Historical and Paleoenvironmental Perspectives. In Antarctic Research Series; Domack, E., Leventer, A., Burnett, A., Bindschadler, R., Convey, P., Kirby, M., Eds.; American Geophysical Union: Washington, DC, USA, 2003.

8. Kim, J.H.; Ahn, I.-Y.; Lee, K.S.; Chung, H.; Choi, H.-G. Vegetation of Barton Peninsula in the neighbourhood of King Sejong Station (King George Island, maritime Antarctic). Polar Biol. 2007, 30, 903-916. [CrossRef]

9. Kim, J.H.; Ahn, I.-Y.; Hong, S.G.; Andreev, M.; Lim, K.-M.; Oh, M.J.; Koh, Y.J.; Hur, J.-S. Lichen flora around the Korean Antarctic Scientific Station, King George Island, Antarctic. J. Microbiol. 2006, 44, 480-491.

10. Rodriguez, J.M.; Passo, A.; Chiapella, J.O. Lichen Species Assemblage gradient in South Shetlands Islands, Antarctica: Relationship to deglaciation and microsite conditions. Polar Biol. 2018, 41, 2523-2531. [CrossRef]

11. Barcikowski, A.; Gurtowska, J. Studies on the biomass of selected species of Antarctic mosses on King George Island, South Shetland Islands, Antarctica. Pol. Polar Res. 1999, 20, 283-290.

12. Ferrari, F.R.; Schaefer, C.E.; Pereira, A.B.; Thomazini, A.; Schmitz, D.; Francelino, M.R. Coupled soil-vegetation changes along a topographic gradient on King George Island, maritime Antarctica. Catena 2021, 198, 105038. [CrossRef]

13. Pereira, A.B.; Spielmann, A.A.; Martins, M.F.N.; Francelino, M.R. Plant communities from ice-free areas of Keller peninsula, King George Island, Antarctica. Oecologia Bras. 2007, 11, 14-22. [CrossRef]

14. Olech, M.; Słaby, A. Changes in the lichen biota of the Lions Rump area, King George Island, Antarctica, over the last 20 years. Polar Biol. 2016, 39, 1499-1503. [CrossRef]

15. Torres-Mellado, G.A.; Jaña, R.; Casanova-Katny, M.A. Antarctic hairgrass expansion in the South Shetland archipelago and Antarctic Peninsula revisited. Polar Biol. 2011, 34, 1679-1688. [CrossRef]

16. Putzke, J.; Athanásio, C.G.; De Albuquerque, M.P.; Victoria, F.C.; Pereira, A.B. Comparative study of moss diversity in South Shetland Islands and in the Antarctic Peninsula. Rev. Chil. Hist. Nat. 2015, 88, 822. [CrossRef]

17. Théau, J.; Peddle, D.R.; Duguay, C.R. Mapping lichen in a caribou habitat of Northern Quebec, Canada, using an enhancement_classification method and spectral mixture analysis. Remote Sens. Environ. 2005, 94, 232-243. [CrossRef]

18. Fretwell, P.T.; Convey, P.; Fleming, A.H.; Peat, H.; Hughes, K.A. Detecting and mapping vegetation distribution on the Antarctic Peninsula from remote sensing data. Polar Biol. 2011, 34, 273-281. [CrossRef]

19. Robin, M.; Chapuis, J.-L.; Lebouvier, M. Remote sensing of vegetation cover change in islands of the Kerguelen archipelago. Polar Biol. 2011, 34, 1689-1700. [CrossRef]

20. Shin, J.-I.; Kim, H.-C.; Kim, S.-I.; Hong, S.G. Vegetation abundance on the Barton Peninsula, Antarctica: Estimation from high-resolution satellite images. Polar Biol. 2014, 37, 1579-1588. [CrossRef]

21. Liu, N.; Treitz, P. Modelling high arctic percent vegetation cover using field digital images and high resolution satellite data. Int. J. Appl. Earth Obs. Geoinf. 2016, 52, 445-456. [CrossRef]

22. Sun, X.; Wu, W.; Li, X.; Xu, X.; Li, J. Vegetation abundance and health mapping over Southwestern Antarctica based on worldview-2 data and a modified spectral mixture analysis. Remote Sens. 2021, 13, 166. [CrossRef]

23. Clark, R.N. Spectroscopy of rocks and minerals, and principles of spectroscopy. Man. Remote Sens. 1999, 3, $2-2$.

24. Goswami, S.; Matharasi, K. Development of a web-based vegetation spectral library (Vsl) for remote sensing research and applications. PeerJ PrePrints 2015, 3, e915v1.

25. Calviño-Cancela, M.; Martín-Herrero, J. Spectral discrimination of vegetation classes in ice-free areas of Antarctica. Remote Sens. 2016, 8, 856. [CrossRef]

26. Jeong, G.; Yoon, H. The Origin of Clay minerals in soils of King George Island, South Shetland Islands, West Antarctica, and its implications for the clay-mineral compositions of marine sediments. J. Sediment. Res. 2001, 71, 833-842. [CrossRef]

27. Lee, Y.I.; Lim, H.S.; Yoon, H.I. Geochemistry of soils of King George Island, South Shetland Islands, West Antarctica: Implications for pedogenesis in cold polar regions. Geochim. Cosmochim. Acta 2004, 68, 4319-4333. [CrossRef]

28. Cho, H.K.; Kim, J.; Jung, Y.; Lee, Y.G.; Lee, B.Y. Recent changes in downward longwave radiation at King Sejong station, Antarctica. J. Clim. 2008, 21, 5764-5776. [CrossRef]

29. Nicodemus, F.E.; Richmond, J.C.; Hsia, J.J.; Ginsberg, I.; Limperis, T. Geometrical considerations and nomenclature for reflectance. NBS Mono. 1992, 160, 4.

30. Painter, T.H.; Molotch, N.P.; Cassidy, M.; Flanner, M.; Steffen, K. Contact spectroscopy for determination of stratigraphy of snow optical grain size. J. Glaciol. 2007, 53, 121-127. [CrossRef]

31. Hueni, A.; Bialek, A. Cause, effect, and correction of field spectroradiometer interchannel radiometric steps. IEEE J. Sel. Top. Appl. Earth Obs. Remote Sens. 2017, 10, 1542-1551. [CrossRef]

32. Mac Arthur, A.; MacLellan, C.J.; Malthus, T. The fields of view and directional response functions of two field spectroradiometers IEEE Trans. Geosci. Remote Sens. 2012, 50, 3892-3907. [CrossRef]

33. Chang, C.-I. Spectral information divergence for hyperspectral image analysis. In Proceedings of the IEEE 1999 International Geoscience and Remote Sensing Symposium, IGARSS'99 (Cat. No.99CH36293), Hamburg, Germany, 28 June-2 July 1999 ; Institute of Electrical and Electronics Engineers (IEEE): Hamburg, Germany, 2003; Volume 1, pp. 509-511.

34. der Meer, F.V. The effectiveness of spectral similarity measures for the analysis of hyperspectral imagery. Int. J. Appl. Earth Obs. Geoinf. 2006, 8, 3-17. [CrossRef] 
35. Van Der Meero, F.; Bakker, W. Cross correlogram spectral matching: Application to surface mineralogical mapping by using AVIRIS data from Cuprite, Nevada. Remote Sens. Environ. 1997, 61, 371-382. [CrossRef]

36. Yuhas, R.H.; Goetz, A.F.; Boardman, J.W. Discrimination among semi-arid landscape endmembers using the Spectral Angle Mapper (Sam). Algorithm 1992, 1, 147-149.

37. Shivakumar, B.R.; Rajashekararadhya, S.V. Performance évaluation of spectral angle mapper and spectral correlation mapper classifiers over multiple remote sensor data. In Proceedings of the 2017 Second International Conference on Electrical, Computer and Communication Technologies (ICECCT), Coimbatore, India, 22-24 February 2017; pp. 1-6. [CrossRef]

38. Kim, S.C. Vegetation Distribution Pattern on Barton Peninsula of King George Island, Antarctica. Ph.D. Thesis, Gangneung-Wonju National University, Wonju, Korea, 2016.

39. Barry, P.; Mendenhall, J.; Jarecke, P.; Folkman, M.; Pearlman, J.; Markham, B. EO-1 Hyperion hyperspectral aggregation and comparison with EO-1 Advanced Land Imager and Landsat 7 ETM+. In Proceedings of the IEEE International Geoscience and Remote Sensing Symposium, Toronto, ON, Canada, 24-28 June 2002; Volume 3, pp. 1648-1651. [CrossRef]

40. Kruse, F.; Lefkoff, A.; Boardman, J.; Heidebrecht, K.; Shapiro, A.; Barloon, P.; Goetz, A. The spectral image processing system (SIPS)-Interactive visualization and analysis of imaging spectrometer data. Remote Sens. Environ. 1993, 44, 145-163. [CrossRef]

41. Keshava, N.; Mustard, J.F. Spectral unmixing. IEEE Signal Process. Mag. 2002, 19, 44-57. [CrossRef]

42. Knipling, E.B. Physical and physiological basis for the reflectance of visible and near-infrared radiation from vegetation. Remote Sens. Environ. 1970, 1, 155-159. [CrossRef]

43. Shengyan, D.; Jidong, G.; Lexiang, Q. Assessment of biochemical concentrations of vegetation using remote sensing technology. J. Geogr. Sci. 2002, 12, 321-330. [CrossRef]

44. Deepak, M.; Keski-Saari, S.; Fauch, L.; Granlund, L.; Oksanen, E.; Keinänen, M. Leaf canopy layers affect spectral reflectance in silver birch. Remote Sens. 2019, 11, 2884. [CrossRef]

45. Granlund, L.; Keski-Saari, S.; Kumpula, T.; Oksanen, E.; Keinänen, M. Imaging lichen water content with visible to mid-wave infrared (400-5500 nm) spectroscopy. Remote Sens. Environ. 2018, 216, 301-310. [CrossRef]

46. Rees, W.; Tutubalina, O.; Golubeva, E. Reflectance spectra of subarctic lichens between 400 and $2400 \mathrm{~nm}$. Remote Sens. Environ. 2004, 90, 281-292. [CrossRef]

47. Daughtry, C.S. Discriminating crop residues from soil by shortwave infrared reflectance. Agron. J. 2001, 93, 125-131. [CrossRef]

48. Bechtel, R.; Rivard, B.; Sánchez-Azofeifa, A. Spectral properties of foliose and crustose lichens based on laboratory experiments. Remote Sens. Environ. 2002, 82, 389-396. [CrossRef]

49. Curran, P.J. Remote sensing of foliar chemistry. Remote Sens. Environ. 1989, 30, 271-278. [CrossRef]

50. Slaton, M.R.; Hunt, E.R.; Smith, W.K. Estimating near-infrared leaf reflectance from leaf structural characteristics. Am. J. Bot. 2001, 88, 278-284. [CrossRef] [PubMed]

51. Kuska, M.T.; Behmann, J.; Mahlein, A.-K. Potential of hyperspectral imaging to detect and identify the impact of chemical warfare compounds on plant tissue. Pure Appl. Chem. 2018, 90, 1615-1624. [CrossRef]

52. Fowbert, J.A. An experimental study of growth in relation to morphology and shoot water content in maritime Antarctic mosses. New Phytol. 1996, 133, 363-373. [CrossRef] [PubMed]

53. Proctor, M.C.; Nagy, Z.; Csintalan, Z.; Takács, Z. Water-content components in bryophytes: Analysis of pressure-volume relationships. J. Exp. Bot. 1998, 49, 1845-1854. [CrossRef]

54. Giacomo, C.; Ettore, L.; Rino, L.; Rosa, L.; Rocchina, G.; Girolamo, D.M.; Patrizia, S. The hyperspectral prisma mission in operations. In Proceedings of the IGARSS 2020-2020 IEEE International Geoscience and Remote Sensing Symposium, Waikoloa, HI, USA, 26 September-2 October 2020; pp. 3282-3285. 